\title{
ARTICLE
}

\section{6-O-angeloylplenolin exerts neuroprotection against lipopolysaccharide-induced neuroinflammation in vitro and in vivo}

\author{
Yi-le Zhou ${ }^{1,3}$, Yong-ming Yan ${ }^{2}$, Si-yi Li ${ }^{1}$, Dan-hua He ${ }^{1}$, Sha Xiong ${ }^{1}$, Su-fen Wei ${ }^{1}$, Wei Liu ${ }^{1}$, Ling Hu ${ }^{3}$, Qi Wang ${ }^{1}$, Hua-feng Pan ${ }^{1}$, \\ Yong-xian Cheng ${ }^{2}$ and Yong-qiang Liu $^{1}$
}

\begin{abstract}
Neuroinflammation is one of the critical events in neurodegenerative diseases, whereas microglia play an important role in the pathogenesis of neuroinflammation. In this study, we investigated the effects of a natural sesquiterpene lactone, 6-Oangeloylplenolin (6-OAP), isolated from the traditional Chinese medicine Centipeda minima (L.) A.Br., on neuroinflammation and the underlying mechanisms. We showed that treatment with lipopolysaccharide (LPS) caused activation of BV2 and primary microglial cells and development of neuroinflammation in vitro, evidenced by increased production of inflammatory cytokines TNF-a and $\mathrm{IL}-1 \beta$, the phosphorylation and nuclear translocation of NF-KB, and the transcriptional upregulation of COX-2 and iNOS, leading to increased production of proinflammatory factors $\mathrm{NO}$ and $\mathrm{PGE}_{2}$. Moreover, LPS treatment induced oxidative stress through increasing the expression levels of NOX2 and NOX4. Pretreatment with 6-OAP $(0.5-4 \mu \mathrm{M})$ dose-dependently attenuated LPS-induced NF-KB activation and oxidative stress, thus suppressed neuroinflammation in the cells. In a mouse model of LPS-induced neuroinflammation, 6-OAP $\left(5-20 \mathrm{mg} \cdot \mathrm{kg}^{-1} \cdot \mathrm{d}^{-1}\right.$, ip, for 7 days before LPS injection) dose-dependently inhibited the production of inflammatory cytokines, the activation of the NF-KB signaling pathway, and the expression of inflammatory enzymes in brain tissues. 6-OAP pretreatment significantly ameliorated the activation of microglia and astrocytes in the brains. 6-OAP at a high dose caused a much stronger antineuroinflammatory effect than dexamethansone (DEX). Furthermore, we demonstrated that 6-OAP pretreatment could inhibit LPS-induced neurite and synaptic loss in vitro and in vivo. In conclusion, our results demonstrate that 6-OAP exerts antineuroinflammatory effects and can be considered a novel drug candidate for the treatment of neuroinflammatory diseases.
\end{abstract}

Keywords: 6-O-angeloylplenolin; Traditional Chinese medicine; LPS; neuroinflammation; microglia; NF-KB; oxidative stress; dexamethansone

Acta Pharmacologica Sinica (2020) 41:10-21; https://doi.org/10.1038/s41401-019-0261-5

\section{INTRODUCTION}

In the central nervous system (CNS), neuroinflammation is regarded as one of the critical events in neurodegenerative diseases [1], including Parkinson's disease, Alzheimer's disease, prion diseases, and multiple sclerosis [2-5]. Microglia, as the main immunoeffectors in the CNS, play a critical role in the occurrence and development of neuroinflammation $[3,6]$. By sensing inflammatory stimuli, microglia can be activated, and morphological changes and the production of inflammatory cytokines, chemokines, and reactive oxygen species (ROS) [7-9], which further induce the activation of astrocytes and cause neuroinflammatory damage [10-12], can occur. Thus, the suppression of microglial activation has been recognized as an attractive option for the alleviation of neuroinflammation-related diseases.

Multiple signaling pathways have been reported to mediate inflammatory progression in the CNS, and the NF-KB signaling pathway is best characterized in the development of neuroinflammation. LPS, as the polysaccharide component of gram-negative bacteria, can bind to toll-like receptor 4 and activate the NF-KB signal pathway [13, 14], and it is most frequently used to investigate the inflammatory responses of microglia. Under normal conditions, IKB family members, such as IKB- $\alpha$ and IKB- $\beta$, bind to NF-KB and sequester it in the cytoplasm. In response to inflammatory stimulation, IKB family members can be phosphorylated and degraded; then NF-KB is activated and allowed to enter the nucleus [15]. Activated NF-KB induces the expression of inflammatory cytokines, such as IL-1 $\beta$ and TNF- $\alpha$; the inflammatory enzymes iNOS and COX- 2 are also regulated by NF$\mathrm{KB}$ and mediate the production of the proinflammatory factors NO and $\mathrm{PGE}_{2}$, which potentiate the pathogenesis of neuroinflammation $[16,17]$. Moreover, inflammation-mediated oxidative stress can further promote the development of neuroinflammation $[18,19]$. Numerous studies have demonstrated that NOX protein family members, such as NOX2 and NOX4, can induce ROS

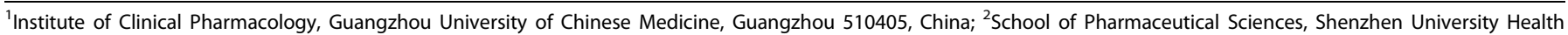
Science Center, Shenzhen 518060, China and ${ }^{3}$ Institute of Gastroenterology, Guangzhou University of Chinese Medicine, Guangzhou 510405, China

Correspondence: Hua-feng Pan (gzphf@gzucm.edu.cn) or Yong-xian Cheng (yxcheng@szu.edu.cn) or Yong-qiang Liu (liuyq@gzucm.edu.cn)

These authors contributed equally: Yi-le Zhou, Yong-ming Yan

Received: 27 December 2018 Accepted: 22 May 2019

Published online: 18 June 2019 
production in activated microglial cells and facilitate the activation of NF-KB [20-23]; meanwhile, NF-KB also exerts positive feedback to regulate the expression of NOX2 and NOX4, which comprehensively induces ROS production [24-26]. As stated above, NF-KB plays a key role in the development of neuroinflammation, which has been widely accepted as a promising therapeutic target for the treatment of neuroinflammatory diseases.

Numerous natural products exert anti-inflammatory activities and have attracted great attention as alternative therapeutic agents against neuroinflammatory diseases [27-29]. C. minima is a traditional Chinese medicine that has antibacterial and antimalarial activities $[30,31]$ and is effective in the treatment of a number of inflammatory diseases, such as arthritis, rhinitis, sinusitis, and diarrhea [32-34]. Furthermore, multiple components, including sesquiterpene lactones, flavonoids, and terpenes, have been purified from C. minima [35-38]; however, the active compounds that have anti-inflammatory activity remain unknown. Previously, 6-OAP was identified as one of the most abundant sesquiterpene lactones isolated from C. minima [39]. 6-OAP has multiple biological activities, including antibacterial, antiprotozoal, and anticancer activities [40-42]. Moreover, 6-OAP has a favorable pharmacokinetic profile and high bioavailability, and no obvious acute toxicity is observed in mice treated with a high dose of 6OAP [41], suggesting that 6-OAP is a safe agent; thus, the therapeutic potential of 6-OAP in anti-inflammatory diseases is worth further investigation.

In this study, we examined the effect and underlying mechanism of 6-OAP in neuroinflammation and assessed its therapeutic potential in LPS-induced neuroinflammatory models both in vitro and in vivo. Our results first demonstrate that 6-OAP exhibits neuroprotective effects via the amelioration of neuroinflammation, suggesting that the natural compound 6-OAP has therapeutic potential in neuroinflammatory diseases.

\section{MATERIALS AND METHODS}

Reagents and antibodies

6-OAP was extracted from C. minima as described, and the purity was as high as 98\% [39]. 6-OAP was dissolved in DMSO at a concentration of $20 \mathrm{mM}$ to produce a stock solution. LPS from Escherichia coli 055:B5 was purchased from Sigma (St. Louis, MO, USA). Hoechst 33342, 2',7'-dichlorodihydrofluorescein diacetate (DCFH-DA) and DAPI were obtained from Beyotime Institute of Biotechnology (Shanghai, China). Celecoxib and DEX were purchased from MCE (Medchem Express, NJ, USA). Antibodies against iNOS, NOX2, NOX4, COX-2, and lamin B1 were obtained from Abcam (Cambridge, MA, USA). Antibodies against IKB-a, phospho-IKB-a, NF-KB p65, phospho-NF-KB p65, synaptophysin (SYN), NeuN, and $\beta$-actin were purchased from Cell Signaling Technology (Beverly, MA, USA). Antibodies against lba1, GFAP, and TNF-a were obtained from Millipore (Bedford, MA, USA). All secondary antibodies (horseradish peroxidase conjugated antirabbit IgG and anti-mouse IgG, Alexa Fluor 594-conjugated goat anti-rabbit IgG and FITC-conjugated goat anti-mouse lgG) were purchased from Cell Signaling Technology.

\section{Cell culture and treatment}

The murine microglial BV2 cell line (passage 4) was purchased from the Interlab Cell Line Collection cell bank (Genova, Italy). The mouse hippocampal neuronal HT22 cell line (passage 4) was purchased from the American Type Culture Collection (ATCC, VA, USA). The BV2 and HT22 cells were cultured in DMEM containing $10 \%$ fetal bovine serum, penicillin $(100 \mathrm{U} / \mathrm{mL})$, and streptomycin $(100 \mu \mathrm{g} / \mathrm{mL})$ in a humidified incubator containing $95 \%$ air and $5 \%$ $\mathrm{CO}_{2}$ at $37^{\circ} \mathrm{C}$. Primary microglia were isolated from the brains of neonatal mice within 3 days of birth by a mild trypsinization method [43]. Briefly, the brains were dissected, cut into $1 \mathrm{~mm}^{3}$ small pieces and incubated with $0.125 \%$ EDTA-free trypsin for 15 $\min$ at $37^{\circ} \mathrm{C}$. The cell suspension was plated and cultured in DMEM with $10 \%$ FBS for 2-3 weeks until the cell confluency reached $90 \%$. Then, the mixed glial cells were incubated with $0.05 \%$ EDTA-free trypsin for $30 \mathrm{~min}$ at $37^{\circ} \mathrm{C}$, and the nondetached cells were further digested with $0.25 \%$ EDTA-free trypsin. The cell suspension was seeded to obtain a homogeneous population of microglial cells. The purity of the microglial cells reached $95 \%$, as determined by Iba1 immunofluorescence staining (Fig. 1j). In the subsequent experiments, the cells were pretreated with the indicated concentrations of 6-OAP for $2 \mathrm{~h}$ prior to the addition of LPS $(1 \mu \mathrm{g} / \mathrm{mL})$. The cerebral cortices of E18 embryos were used to prepare neurons as described previously [44]. The cells were maintained in neurobasal medium supplemented with B27 (2\%) and L-glutamine $(2 \mathrm{mM})$ and plated on poly-D-lysine-coated 24 well plates $\left(2 \times 10^{5}\right.$ neurons/well). The medium was changed $24 \mathrm{~h}$ after plating and every 2 days thereafter. Neurons cultured for 7 days were used in the experiments.

Coculture experiment and neurite outgrowth assay

To investigate the neuroprotective effects of 6-OAP, primary cortical neuron and BV2 cell coculture experiments were performed using Transwell plates $(0.4 \mu \mathrm{m}$, Corning Costar, St. Louis, MO, USA). BV2 cells were plated in the inserts, pretreated with or without 6-OAP for $2 \mathrm{~h}$ and then stimulated with $1 \mu \mathrm{g} / \mathrm{mL}$ LPS for another $2 \mathrm{~h}$. The inserts containing BV-2 cells were then washed with neurobasal medium before being placed in 24-well plates containing neurons. For the neurite outgrowth assay, $24 \mathrm{~h}$ after coculture, bright field images were acquired using a Leica light microscope (Leica, Wetzlar, Germany). The total neurite length was determined using NeuronJ [45]. Four random microscope fields per condition were quantified, and the ratio between the total neurite length and the number of neurons was used to calculate the average neurite length.

\section{Animals}

All experiments in this study were approved by and in accordance with the guidelines of the Animal Ethics Committee of Guangzhou University of Chinese Medicine. Six-week-old male C57BL/6J mice were purchased from Vital River Laboratory Animal Technology (Beijing, China). All mice were kept at $23 \pm 1{ }^{\circ} \mathrm{C}$ under a $12 \mathrm{~h}$ light/ dark cycle and had access to water and food ad libitum for at least 1 week before the experiment. The mice were randomly divided into six groups ( $n=12$ per group): vehicle control (5\% cremophor/ $5 \%$ ethanol in normal saline), LPS $(2 \mathrm{mg} / \mathrm{kg}), \operatorname{LPS}+6-\mathrm{OAP}(5,10$, $20 \mathrm{mg} / \mathrm{kg}$ ) and LPS + DEX (1 mg/kg). DEX was used as an antiinflammatory positive control. Intraperitoneal (i.p.) injections of 6OAP and DEX were administered for 7 consecutive days prior to a single i.p. injection of LPS, while the control group received an equal volume of saline. The mice were sacrificed 1 day after LPS administration, and the brain tissues were collected for subsequent experiments.

Cell viability assay

A 3-(4,5-dimethyl thiazol-2-yl)-2,5-diphenyl tetrazolium bromide (MTT) assay was used to detect cell viability in 96-well plates. Cells $\left(1 \times 10^{4}\right)$ were plated in each well and treated with LPS for $24 \mathrm{~h}$ with or without 6-OAP, $10 \mu \mathrm{L}$ of MTT working solution containing $5 \mathrm{mg} / \mathrm{mL}$ MTT was added to each well and the plates were incubated for $4 \mathrm{~h}$ at $37^{\circ} \mathrm{C}$. Then, the supernatant was removed, and the formazan crystal products were dissolved in $150 \mu \mathrm{L}$ DMSO. The absorbance at $490 \mathrm{~nm}$ was detected, and the results were expressed as the mean percentage of absorbance in the treated versus control cells.

\section{Nitrite oxide (NO) assay}

NO production was detected by a Griess kit (Beyotime Institute of Biotechnology). In short, the cell supernatants were collected and centrifuged at $1000 \mathrm{r} / \mathrm{min}$ after $24 \mathrm{~h}$ treatment with LPS in the 
a

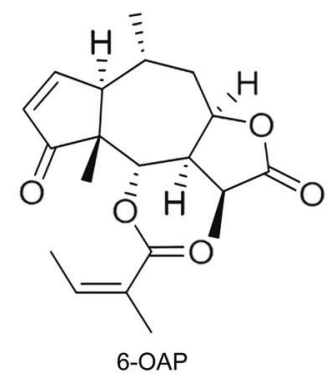

d

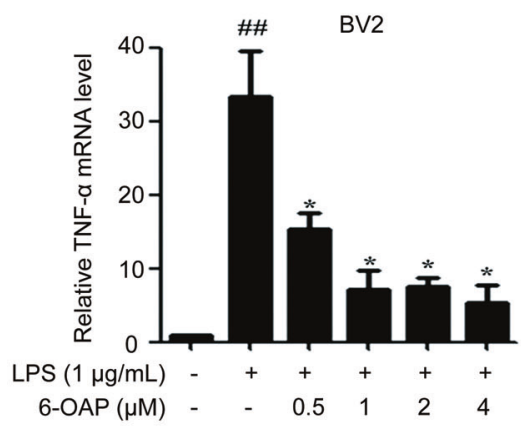

g

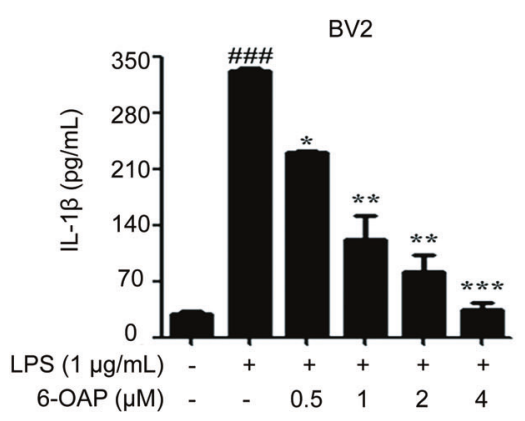

j

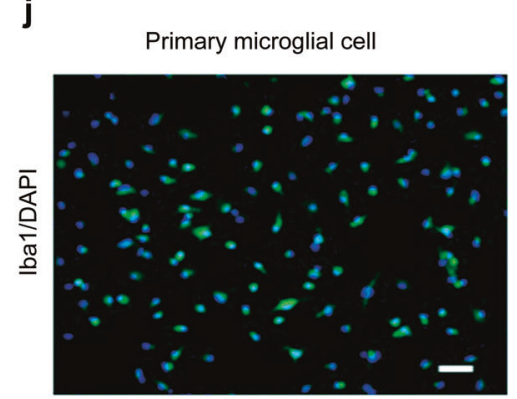

b

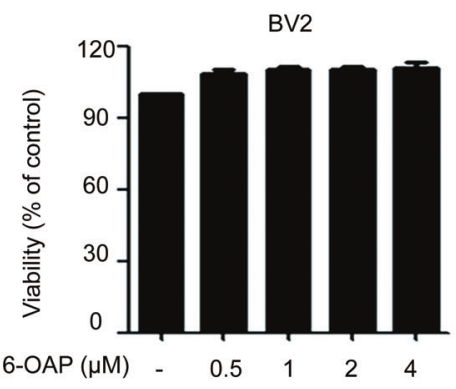

e

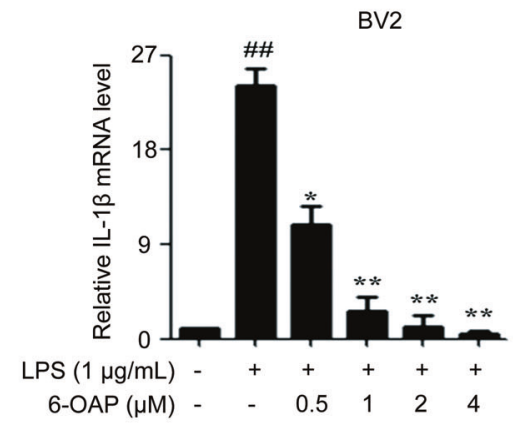

h

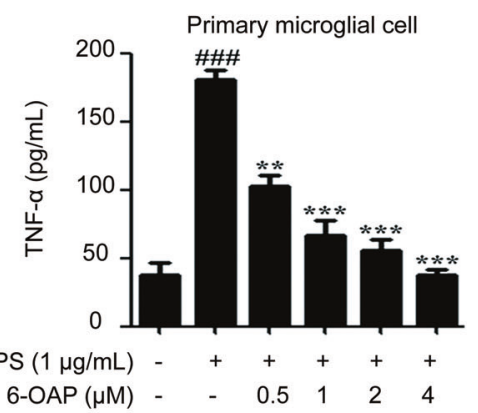

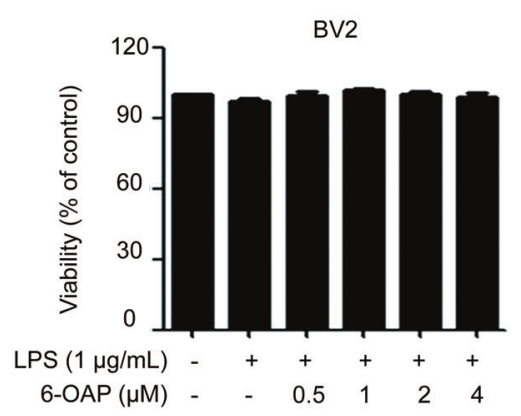

f

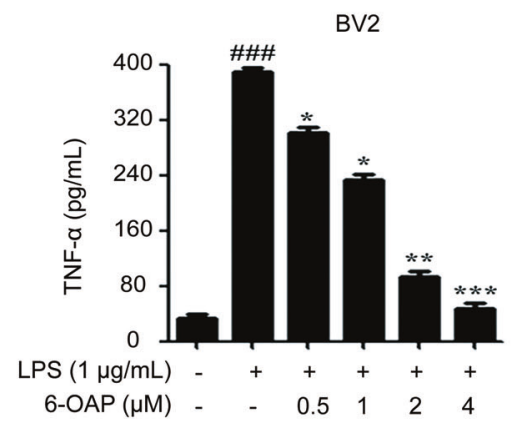

i

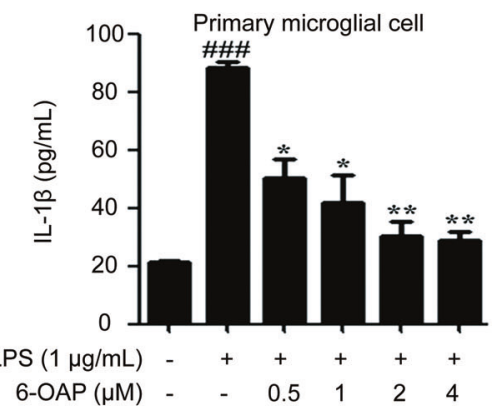

$\mathbf{k}$

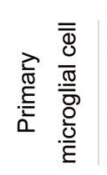

Control LPS $(1 \mu \mathrm{g} / \mathrm{mL})$

LPS + 6-OAP $(1 \mu \mathrm{M}) \quad$ LPS $+6-$ OAP $(4 \mu \mathrm{M})$
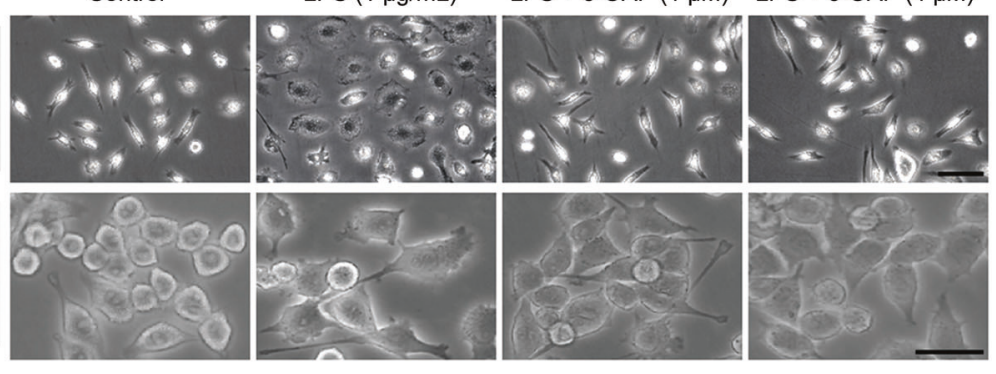

ัั
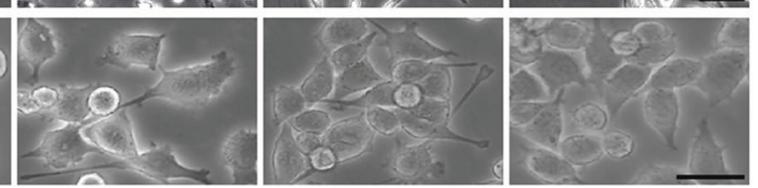

Fig. 1 6-OAP inhibits the activation of microglial cells. a Chemical structure of 6-OAP. b, c The percentage of cell viability for $24 \mathrm{~h}$ in BV2 cells was determined by a MTT assay. $\mathbf{d}$, $\mathbf{e}$ The relative mRNA levels of TNF- $\alpha$ and IL-1 $\beta$ in BV2 cells were detected by real-time PCR analysis. $\mathbf{f}-\mathbf{i}$ The production of TNF- $\alpha$ and IL-1 $\beta$ in BV2 $(\mathbf{f}, \mathbf{g})$ and primary microglial cells $(\mathbf{h}, \mathbf{i})$ were examined by ELISA. $\mathbf{j}$ Primary microglia was stained using Iba1 antibody (green) and DAPI (blue), purity of primary microglia can reach $95 \%$. k Morphological changes of primary microglial cells (upper panal) and BV2 cells (lower panal) were observed under bright field of microscope, and representative pictures have been shown for comparison. Scale bar, $20 \mu \mathrm{m}$. All data are presented as the means \pm SEM from three separate experiments. ${ }^{\#} P<0.01$, \#\#\# $P<0.001$ versus control cells. ${ }^{*} P<0.05,{ }^{* *} P<0.01,{ }^{* * *} P<0.001$ versus LPS alone

presence or absence of 6-OAP. Fifty microliters of each cell supernatant were collected, equal volumes of Griess reagent I and II working solutions were added, and the absorbance at a wavelength of $540 \mathrm{~nm}$ was measured within 10 min using a microplate reader. Sodium nitrite was used as a standard in the assay. 
ELISA for TNF- $\alpha$, IL-1 $\beta$, and PGE 2

The concentrations of TNF- $\alpha$ and IL-1 $\beta$ were examined by using mouse TNF- $\alpha$ and IL-1 $\beta$ ELISA (Neobioscience Technology Co., Ltd., China), and $\mathrm{PGE}_{2}$ was quantified using a competitive ELISA (Cusabio Biotech, China). Briefly, BV2 and primary microglial cells were stimulated with LPS $(1 \mu \mathrm{g} / \mathrm{mL})$ with or without 6-OAP, and the supernatants were collected and centrifuged after $8 \mathrm{~h}$ of treatment for TNF- $\alpha$ and IL-1 $\beta$ detection and after $24 \mathrm{~h}$ of treatment for $\mathrm{PGE}_{2}$ detection. For the in vivo test, brain tissues were homogenized with cold PBS and centrifuged, and the supernatants were collected for the detection of TNF- $\alpha$ and IL-1 $\beta$. The absorbance was read at a wavelength/reference wavelength of $450 / 650 \mathrm{~nm}$ on a microplate reader, according to the manufacturer's instructions. The concentrations of TNF- $a, I L-1 \beta$, and $\mathrm{PGE}_{2}$ were calculated according to the standard curve and are presented as $\mathrm{pg} / \mathrm{mL}$.

Extracting cytoplasmic and nuclear proteins

BV2 cells and primary microglial cells were pretreated with the indicated concentrations of 6-OAP for $2 \mathrm{~h}$ and then stimulated with LPS $(1 \mu \mathrm{g} / \mathrm{mL})$ for $1 \mathrm{~h}$. The cultured cells were harvested and washed twice with cold phosphate-buffered saline (PBS) after LPS stimulation. The cytoplasmic and nuclear protein fractions were extracted using a Nuclear and Cytoplasmic Extraction Kit (Beyotime Institute of Biotechnology) according to the manufacturer's protocol.

Western blotting

At the end of LPS treatment, the cells and tissues were harvested and lysed using RIPA lysis buffer. After the quantification of the protein samples using a BCA Protein Assay Kit (Beyotime Institute of Biotechnology), equal amounts of protein per sample were loaded in each lane, separated by $10 \%$ SDS-PAGE, and transferred to PVDF membranes. The membranes were blocked with $5 \%$ skim milk for $2 \mathrm{~h}$ at room temperature and incubated with the indicated antibodies overnight at $4{ }^{\circ} \mathrm{C}$. The PVDF membranes were further incubated with HRP-conjugated secondary antibodies for $2 \mathrm{~h}$ at room temperature. The protein bands were visualized using Immobilon Western HRP Substrate Luminol Reagent (Millipore, MA, USA). Images were obtained using a ChemiDoc XRS system with Quantity One software (Bio-Rad, CA, USA). The densitometry analysis of the immunoblots was performed using ImageJ software ( $\mathrm{NIH}, \mathrm{USA})$. The assays were performed in triplicate.

Real-time PCR

Total RNA was isolated from microglial cells and tissues using TRIzol $^{\mathrm{TM}}$ reagent according to the manufacturer's instructions. Total RNA $(1 \mu \mathrm{g})$ was reverse-transcribed using a One Step PrimeScript ${ }^{\mathrm{TM}}$ RT-PCR Kit and a thermocycler. Real-time PCR for TNF- $\alpha$ and IL-1 $\beta$ was performed in triplicate using ChamQTM Universal SYBR qPCR Master Mix (all reagents above were from Vazyme Biotech Co., Ltd., Nanjing, China) and an ABI 7500 sequence detection system. The primer sequences used are available upon request.

Measurement of the intracellular redox state

DCFH-DA, as an oxidation-sensitive fluorescent probe, was used to analyze the total intracellular content of ROS according to standard protocols. In short, BV2 cells were incubated with $5 \mu \mathrm{M}$ DCFH-DA in phenol red-free DMEM for $30 \mathrm{~min}$ at $37^{\circ} \mathrm{C}$ after $24 \mathrm{~h}$ of LPS stimulation. The cells were then washed with PBS and stained with Hoechst 33342 for $5 \mathrm{~min}$. The ROS levels were monitored using a Leica fluorescence microscope (Leica, Wetzlar, Germany). For the quantification of ROS production, the cells in each treatment group were lysed with NP-40 lysis buffer after incubation with DCFH-DA, and the fluorescence intensity was recorded with a fluorimetric plate reader (excitation at $504 \mathrm{~nm}$, emission at $529 \mathrm{~nm}$; Perkin-Elmer, MA, USA).
Immunofluorescence staining

For the in vivo experiments, mice were perfused with PBS followed by $4 \%$ paraformaldehyde (PFA). The brains were removed and fixed overnight in 4\% PFA, cryoprotected with $30 \%$ sucrose in PBS, and frozen in Tissue Tek-OCT (Sakura Finetek, CA, USA). Coronal sections $(12 \mu \mathrm{m})$ were prepared using a Leica CM 3000 cryostat. For the in vitro experiments, BV2 and primary microglial cells were pretreated with the indicated concentrations of 6-OAP for $2 \mathrm{~h}$ and then stimulated with LPS $(1 \mu \mathrm{g} / \mathrm{mL})$ for an additional $1 \mathrm{~h}$. The immunofluorescence staining of sections and cultured cells was carried out according to standard protocols. Briefly, the sections or cells were fixed with 4\% PFA for $15 \mathrm{~min}$, blocked and permeabilized with PBST (PBS with $0.1 \%$ Triton X-100) containing $10 \%$ normal goat serum for $60 \mathrm{~min}$ at room temperature, incubated with the indicated primary antibody (1:500) at $4{ }^{\circ} \mathrm{C}$ overnight, and stained with the corresponding secondary antibody (Alexa Fluor 594 goat anti-rabbit lgG or FITC goat anti-mouse lgG, 1:500) for $2 \mathrm{~h}$ at room temperature. The sections or cells were counterstained with DAPI or Hoechst 33342 and mounted with Fluoromount G. Images were acquired using a confocal laser scanning microscope (Leica) or Leica fluorescence microscope. To count the cells for each condition of the animal experiments, six coronal sections from different levels across the anteroposterior axis of the hippocampus were chosen for immunostaining, and at least five images (picture size: 622.18 $\mu \mathrm{m} \times 466.55 \mu \mathrm{m}$ ) were taken from the hippocampus, including the CA1 and dentate gyrus regions, of each brain section (Supplementary Fig. 2). The cells were counted semiautomatically using the 'Analyze Particles' function in ImageJ. In brief, the fluorescent images were converted to black and white following background subtraction, and the threshold was set at a level of 50 out of 255 . Then, the cell size was set as '150-infinity' to include nearly all cell particles using the 'Analyze Particles' function in ImageJ. The parameters were kept identical for all images to maintain consistency.

\section{Statistical analysis}

All quantitative measures are presented as the mean \pm standard error of the mean. An unpaired $t$ test was performed to compare two samples to determine the statistical significance of the difference. $P<0.05$ was considered statistically significant. Data handling and statistical processing were performed using GraphPad Prism 7.0 (GraphPad Software, San Diego, CA, USA). All experiments were performed at least three times.

\section{RESULTS}

6-OAP inhibits the LPS-induced production of inflammatory mediators in microglial cells

To determine the antineuroinflammatory activity of 6-OAP (Fig. 1a), we first examined the drug toxicity of 6-OAP in BV2 microglial cells. As shown in Fig. 1b, $c, 6-O A P$ at the indicated concentrations with or without LPS treatment did not affect the viability of BV2 cells, thus excluding the possibility of toxic effects of 6-OAP. Subsequently, we examined the inhibitory effects of 6-OAP on the activation of microglial cells. Upon LPS stimulation, the mRNA levels of the proinflammatory cytokines TNF- $\alpha$ and IL-1 $\beta$ were significantly increased, whereas 6-OAP treatment significantly inhibited the LPS-induced upregulation of proinflammatory cytokines in BV2 cells, as determined by real-time PCR analysis (Fig. 1d, e). Consistently, ELISA also confirmed that 6-OAP was able to inhibit the production of TNF$a$ and IL-1 $\beta$ induced by LPS in BV2 (Fig. 1f, g) and primary microglial cells (Fig. 1h, i). Studies have reported that the activation of microglia can be reflected by morphological changes [46], and we observed that rod-shaped primary microglia were markedly transformed into amoeboid microglia after $24 \mathrm{~h}$ of LPS treatment (Fig. 1j, k); consistently, the 
a

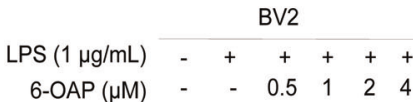

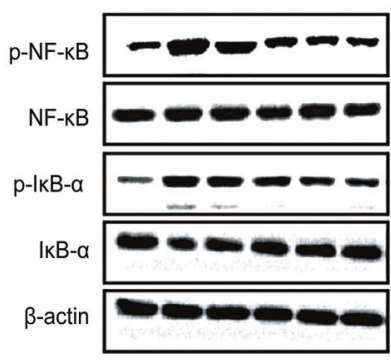

b

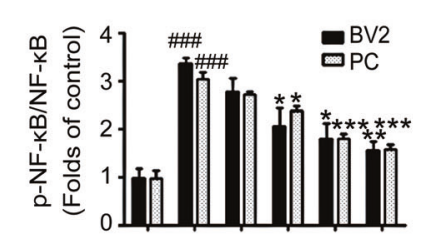

Primary microglial cells
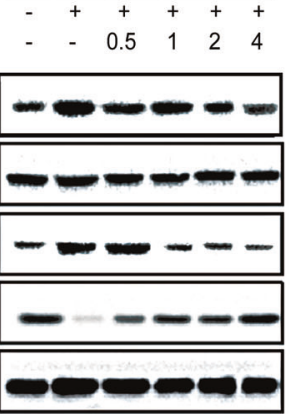

e

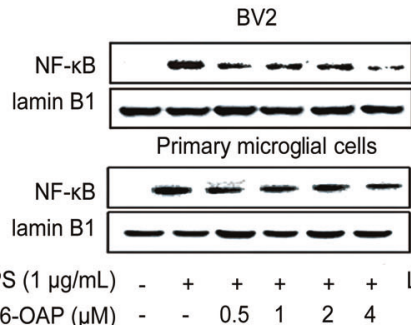

f

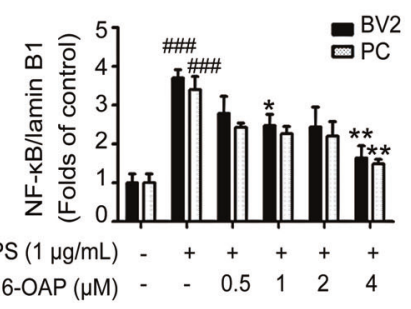

d h

LPS $(1 \mu \mathrm{g} / \mathrm{mL})$
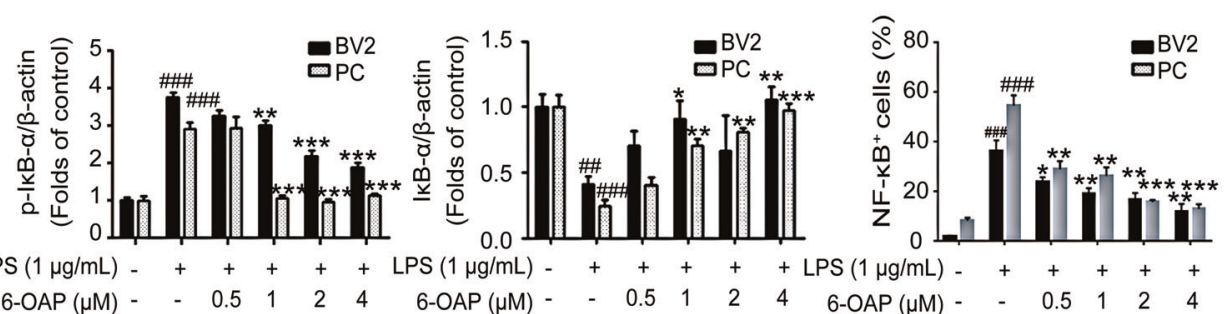

LPS $(1 \mu \mathrm{g} / \mathrm{mL})$ $++++\operatorname{LPS}(1 \mu \mathrm{g} / \mathrm{mL})-$ $6-\mathrm{OAP}(\mu \mathrm{M})$ -

g

Control

$\operatorname{LPS}(1 \mu \mathrm{g} / \mathrm{mL})$
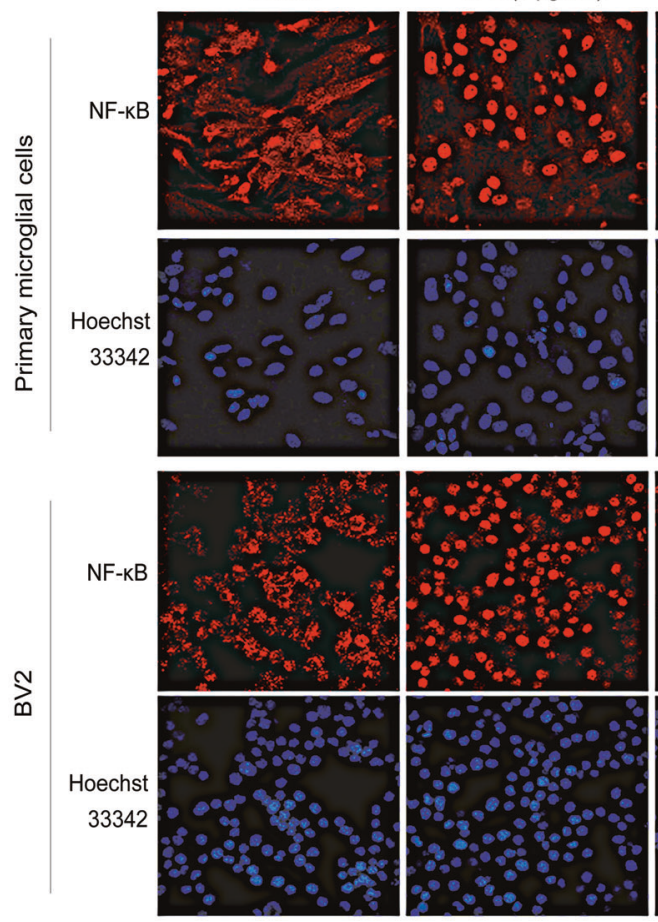

LPS+6-OAP $(0.5 \mu \mathrm{M})$

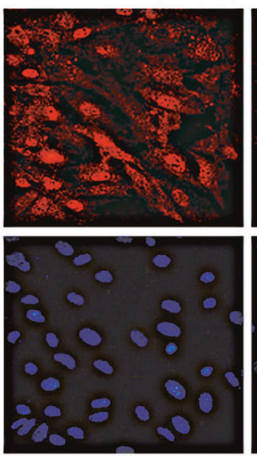

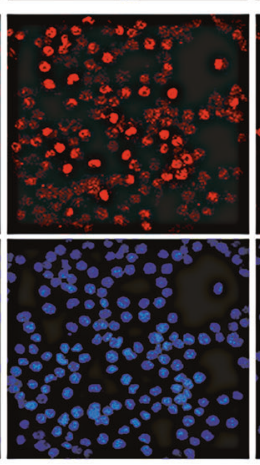

LPS+6-OAP (1 $\mu \mathrm{M})$

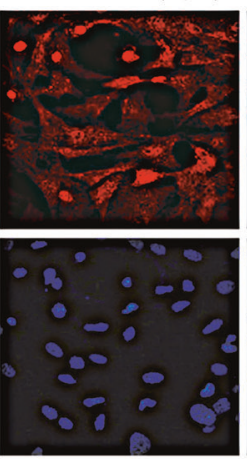

LPS+6-OAP $(2 \mu \mathrm{M})$
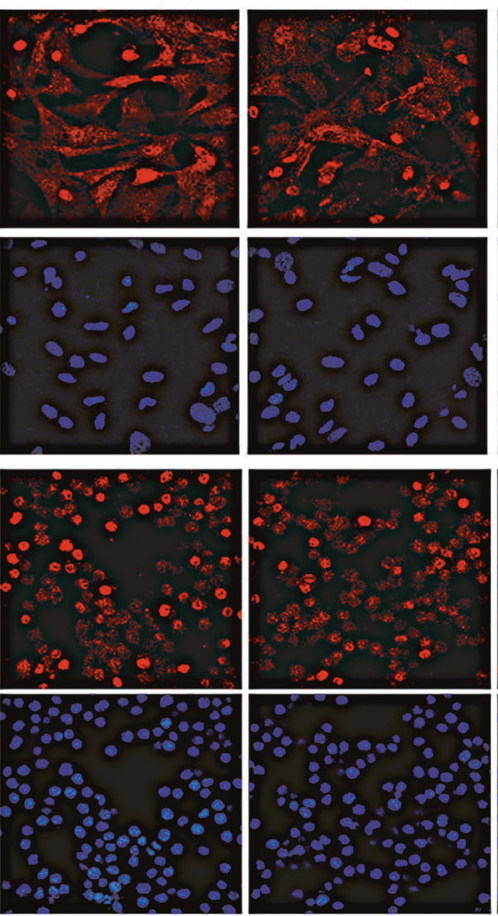

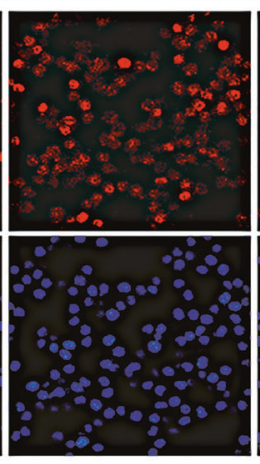

LPS+6-OAP $(4 \mu \mathrm{M})$
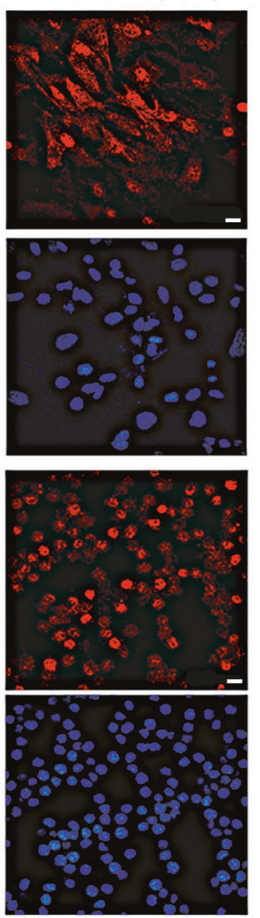

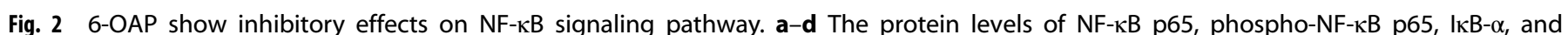
phospho-IKB- $\alpha$ were analyzed by Western blotting, $\beta$-actin was used as a loading control. e, $\mathbf{f}$ The nuclear part of NF- $\mathrm{KB}$ was detected by western blotting, lamin B1 was used as a loading control. $\mathbf{g}$ Nuclear localization of NF- $\kappa$ B of primary microglial cells (upper panal) and BV2 cells (lower panal) was determined by immunostaining with NF-kB subunit p65 (red), and counterstained with Hoechst 33342 (blue), the images were obtained by confocal microscopy. $\mathbf{h}$ The percentage of nuclear NF-kB-positive cells among cultured microglial cells was quantified. Scale bar, $20 \mu \mathrm{m}$. Relative protein levels were quantified by densitometry analysis using ImageJ software. Data are presented as the means \pm SEM from three separate experiments. ${ }^{\# \#} P<0.01$, ${ }^{\# \# \# P} P<0.001$ versus control cells. ${ }^{*} P<0.05,{ }^{* *} P<0.01$, ${ }^{* * *} P<0.01$ versus LPS alone. $\mathrm{p}-\mathrm{NF}$ - $\mathrm{kB}$ :

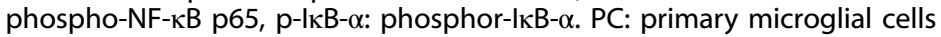

morphology of BV2 cells was converted from a bipolar to an amoeboid shape, and the cell bodies were enlarged after LPS stimulation (Fig. 1k); furthering demonstrating that BV2 cells were markedly activated by inflammatory stimulation. However,
6-OAP treatment obviously reversed the morphological changes caused by LPS (Fig. 1k). The results above suggest that 6-OAP exerts antineuroinflammatory effects via the attenuation of microglial cell activation. 


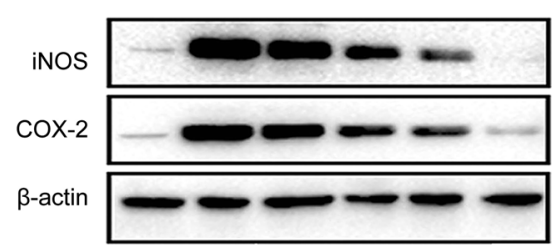

Primary microglial cells

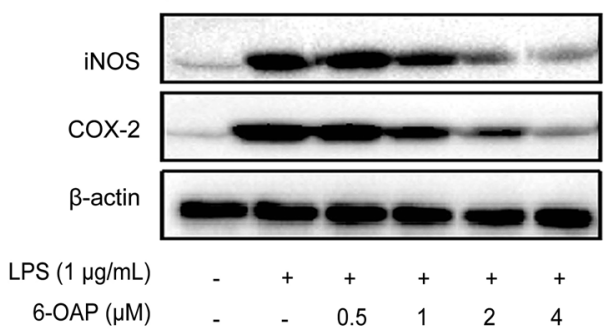

b
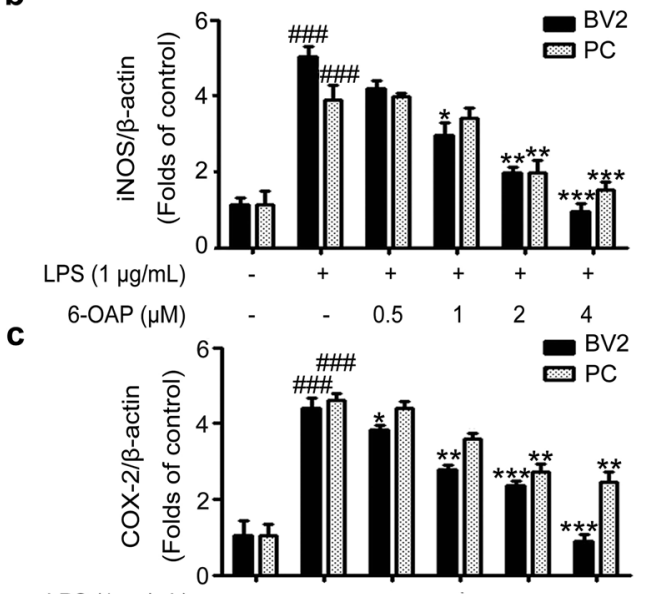

LPS $(1 \mu \mathrm{g} / \mathrm{mL})$

6-OAP $(\mu \mathrm{M})$

BV2

f
BV2 d

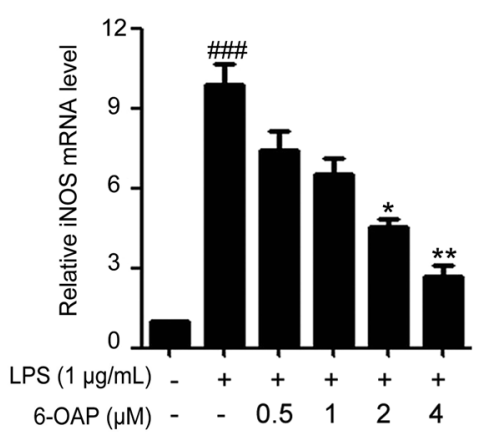

g

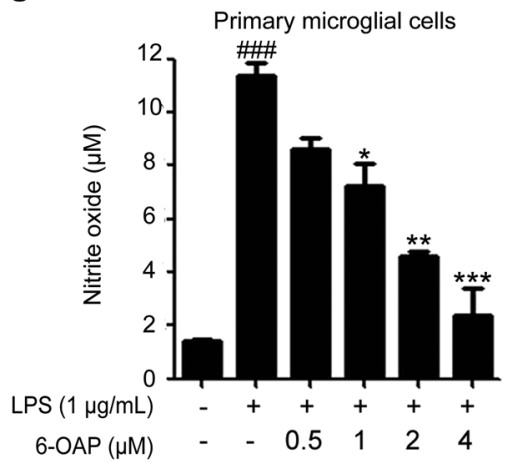

e

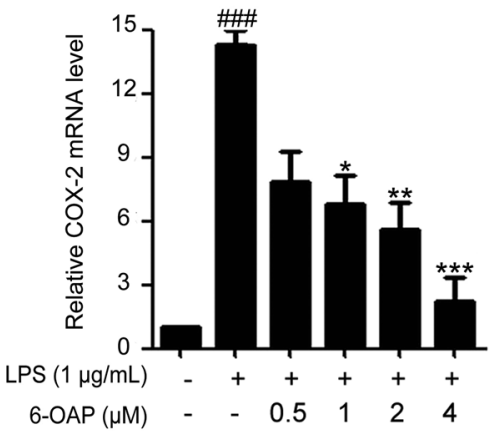

h

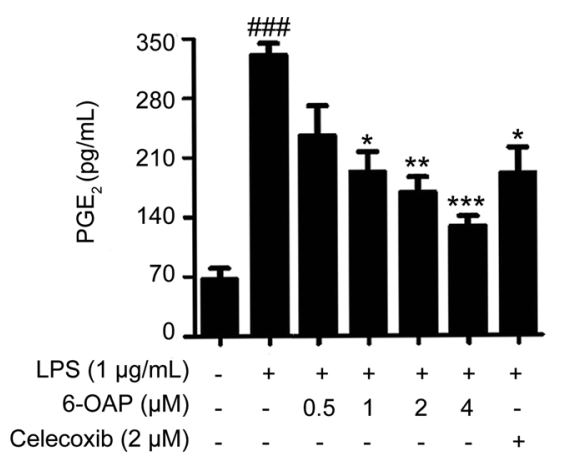

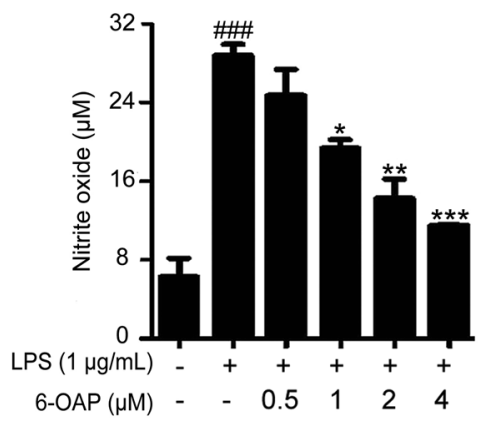

i
BV2

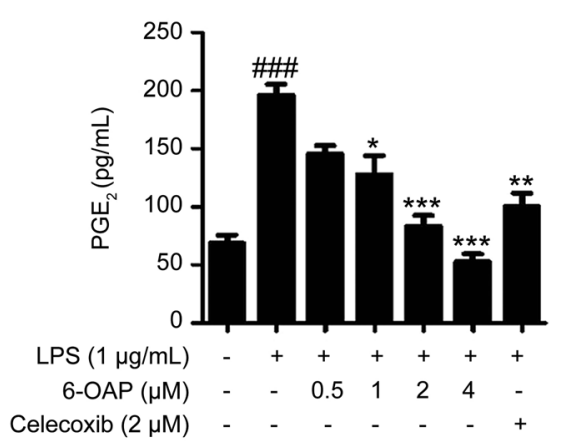

Fig. 3 6-OAP suppresses the LPS-induced expression of iNOS and COX-2. a-c The protein levels of iNOS and COX-2 in BV2 and primary microglial cells after $24 \mathrm{~h}$ treatment were analyzed by Western blotting, $\beta$-actin was used as an internal control. $\mathbf{d}$, e The relative mRNA levels of iNOS and COX-2 in BV2 cells were detected by real-time PCR analysis. $\mathbf{f}-\mathbf{i}$ Culture supernatants of BV2 and primary microglial cells were harvested after $24 \mathrm{~h}$ treatment, the concentration of Nitrite oxide $(\mathbf{f}, \mathbf{g})$ and $\mathrm{PGE}_{2}(\mathbf{h}, \mathbf{i})$ were determined and quantified using the Griess reagent and competitive ELISA, respectively. Celecoxib was used as a positive control for COX-2 inhibition. Relative protein levels were quantified by densitometry analysis using ImageJ software. The quantification from three independent experiments was analyzed and expressed as means \pm SEM. ${ }^{\# \#} P<0.001$ versus control group, ${ }^{*} P<0.05$, ${ }^{*} P<0.01$, and ${ }^{* *} P<0.001$ versus LPS group. PC: primary microglial cells

6-OAP exhibits antineuroinflammatory effects through inhibiting the NF-KB signaling pathway

NF-KB plays a key role in the transcriptional regulation of inflammatory cytokines and the development of inflammation. Thus, we examined whether 6-OAP can inhibit neuroinflammation by regulating NF-KB activity in microglial cells. As shown in Fig. 2a, LPS stimulation increased the phosphorylation of NF-KB rapidly within $30 \mathrm{~min}$, while IKB-a was phosphorylated and degraded. However, 6-OAP treatment significantly inhibited the phosphorylation of NF-KB and reversed the phosphorylation and downregulation of $1 \mathrm{~KB}-\mathrm{a}$ induced by LPS in BV2 and primary microglial cells (Fig. 2a-d). Activated NF-KB can enter the nucleus and initiate transcription. Thus, we examined the effect of 6-OAP on the nuclear translocation of NF-KB induced by LPS. Upon LPS stimulation for $1 \mathrm{~h}$, nuclear NF-KB increased obviously in BV2 and primary microglial cells, as determined by Western 
a

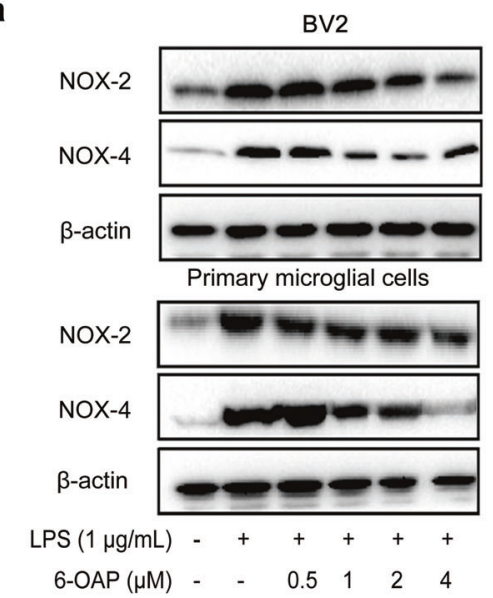

b
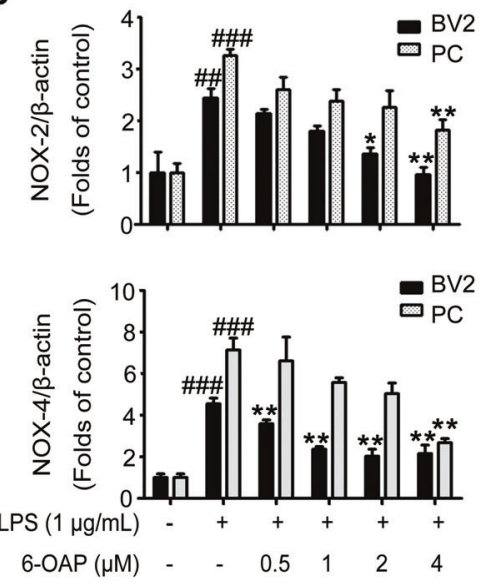

d

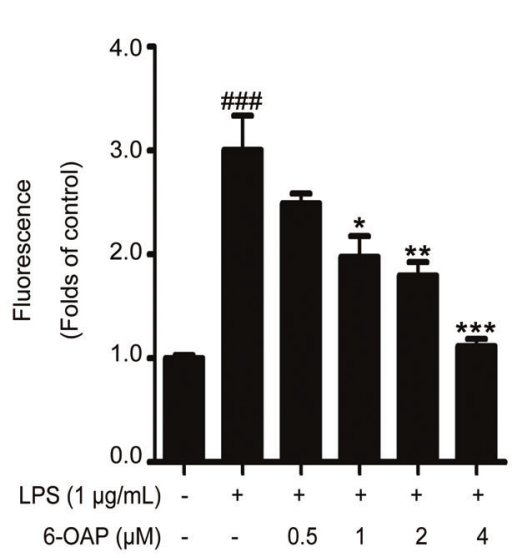

C

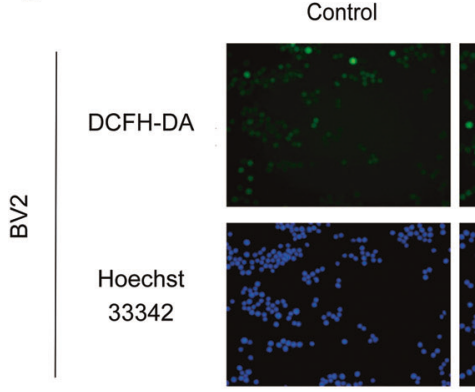
$\operatorname{LPS}(1 \mu \mathrm{g} / \mathrm{mL})$

LPS+6-OAP $(0.5 \mu \mathrm{M})$

LPS+6-OAP $(1 \mu \mathrm{M})$

LPS+6-OAP $(2 \mu \mathrm{M})$

LPS+6-OAP $(4 \mu M)$
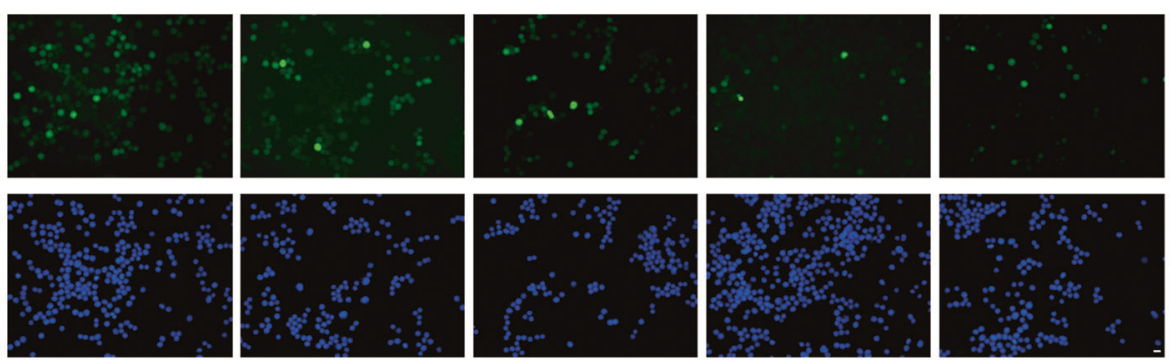

Fig. 4 6-OAP attenuates inflammation-induced oxidative stress. a, b The expression levels of NOX-2 and NOX-4 were examined by Western blotting, $\beta$-actin was used as an internal control, relative protein levels were quantified by densitometry analysis using ImageJ software. c The intracellular level of ROS was determined by using the fluorescent probe DCFH-DA, and representative pictures were shown. $\mathbf{d}$ The fluorescence intensity of DCFH-DA was quantified using fluorimetric plate reader, and the relative fluorescence was normalized to control group, and expressed as the means \pm SEM from three independent experiments. ${ }^{\# \#} P<0.01,{ }^{\# \#} P<0.001$ versus control group. ${ }^{*} P<0.05,{ }^{* *} P<$ $0.01,{ }^{* * *} P<0.001$ versus LPS-stimulated cells. PC: primary microglial cells

blotting, whereas pretreatment with 6-OAP blocked the LPSinduced nuclear translocation of NF-KB (Fig. 2e, f). Moreover, immunostaining was performed to confirm the effect of 6-OAP on NF-KB cellular distribution in microglial cells. We also found that 6-OAP inhibited the LPS-induced nuclear distribution of NF$\mathrm{KB}$ in primary microglial cells and BV2 cells (Fig. $2 g, h$ ), indicating that the natural compound 6-OAP can suppress the development of neuroinflammation by inhibiting the NF-KB signaling pathway.

6-OAP suppresses iNOS and COX-2 expression induced by LPS in microglial cells

Inflammatory enzymes, such as iNOS and COX-2, can be upregulated by activated NF-KB and augment the inflammatory response through the production of $\mathrm{NO}$ and $\mathrm{PGE}_{2}$. Thus, we examined the effect of 6-OAP on iNOS and COX-2 expression. As shown in Fig. 3a, LPS treatment markedly increased the protein levels of iNOS and COX-2 in BV2 and primary microglial cells, and the effects were attenuated by 6-OAP (Fig. 3a-c). Furthermore, we found that 6-OAP decreased the mRNA levels of iNOS and COX-2 induced by LPS in BV2 cells (Fig. 3d, e), indicating that 6-OAP regulates the expression of iNOS and COX-2 at the transcriptional level. Consistently, 6-OAP treatment significantly suppressed the production of $\mathrm{NO}$ (Fig. 3f, g) and $\mathrm{PGE}_{2}$ (Fig. 3h, i) induced by LPS in BV2 and primary microglial cells, demonstrating that 6-OAP exerts inhibitory effects on the expression of inflammatory enzymes and the secretion of inflammatory mediators.
6-OAP ameliorates inflammation-induced oxidative stress through decreasing the expression of NOX proteins

Neuroinflammation is frequently accompanied by the increased production of superoxide and ROS [21], and NOX protein family members, such as NOX-2 and NOX-4, can produce high levels of ROS in response to brain injury and inflammation [10]. Thus, we further examined whether 6-OAP regulates inflammation-related ROS production. We found that high expression levels of NOX-2 and NOX-4 were induced by LPS in BV2 and primary microglial cells (Fig. 4a, b); consistently, elevated intracellular ROS production was observed in BV2 cells (Fig. 4c, d). However, when BV2 and primary microglial cells were pretreated with 6-OAP, the induction of NOX-2 and NOX-4 by LPS was markedly attenuated (Fig. 4a, b); meanwhile, LPS-induced ROS production was decreased in BV2 cells (Fig. 4c, d). The results demonstrate that 6 -OAP has a potential role in ameliorating neuroinflammation-induced oxidative stress.

6-OAP protects neurons from microglia-mediated inflammatory injury

The production of proinflammatory mediators and ROS induced by LPS in microglia can potentially cause neuronal damage $[9,10]$. Thus, we tested the neuroprotective effects of 6-OAP against microglia-mediated inflammatory injury. First, we detected the toxicity of 6-OAP in HT22 hippocampal neuronal cells and found that 6-OAP did not show any cytotoxicity based on a cell viability assay (Fig. 5a), indicating that 6-OAP at the tested concentrations is nontoxic to HT22 cells. For cocultures of microglial cells and 


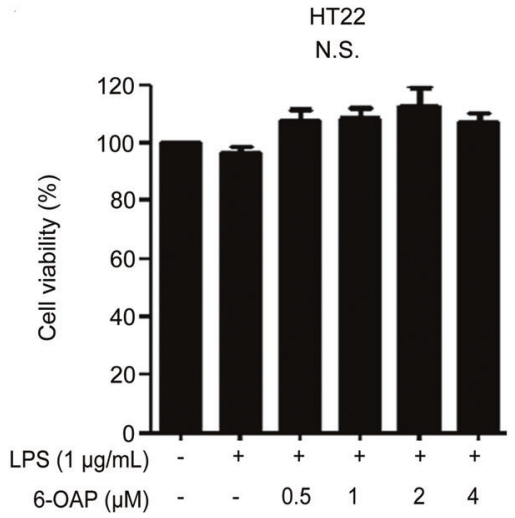

b

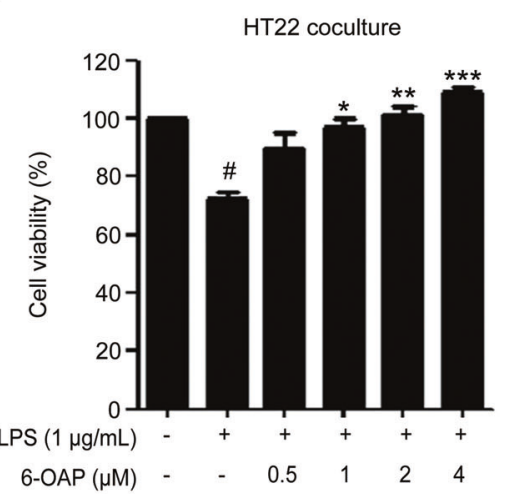

d

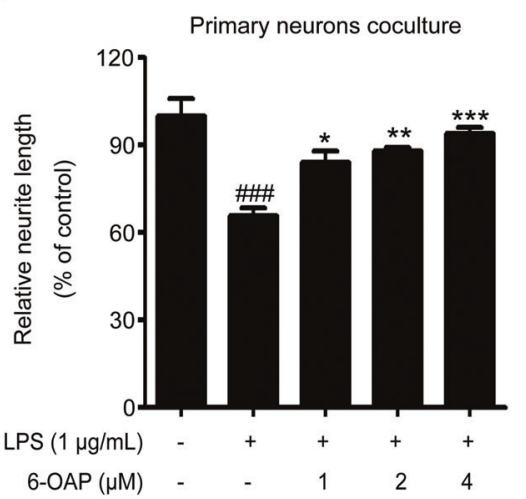

C

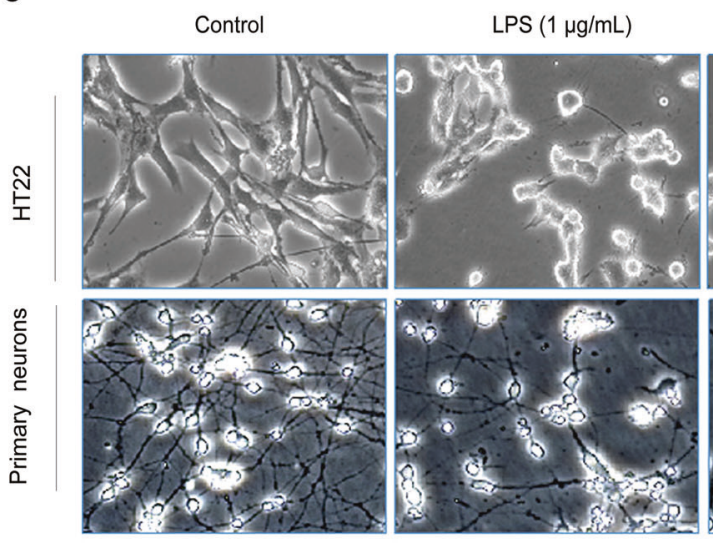

LPS+6-OAP $(0.5 \mu \mathrm{M})$

LPS+6-OAP $(1 \mu \mathrm{M})$

LPS+6-OAP $(2 \mu \mathrm{M})$
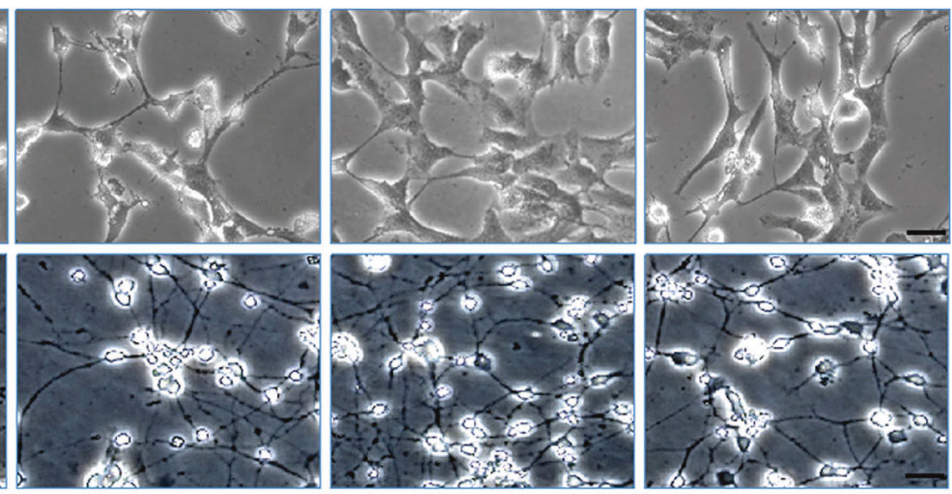

Fig. 5 6-OAP exerts neuroprotective effects against inflammatory injury. $\mathbf{a}$, b The percentage of cell viability of HT22 cells treated with indicated drugs (a) or cultured under conditioned medium (b) for $24 \mathrm{~h}$ was determined by MTT assay. c Morphological changes of HT22 cells (upper panel) and primary cortical neurons (lower panel) were observed, and representative pictures have been taken for comparison. d Neurite lengths of primary cortical neurons were measured by NeuronJ, the relative average neurite length is normalized to control group. Scale bar, $20 \mu \mathrm{m}$. All data are normalized to control cells and presented as the mean \pm SEM of three independent experiments. ${ }^{\#} P<0.05$ versus control group. ${ }^{*} P<0.05,{ }^{* *} P<0.01,{ }^{* *} P<0.001$ versus LPS-stimulated cells. N.S.: non-statistical significant

neurons, conditioned medium harvested from BV2 cells was used to culture HT22 cells. As expected, the LPS-conditioned medium (LPS-CM) from the BV2 cells significantly decreased the cell viability of the HT22 cells within $24 \mathrm{~h}$, whereas the conditioned medium harvested from the BV2 cells that were cotreated with LPS and 6-OAP (6-OAP-CM) was less cytotoxic than the LPS-CM (Fig. 5b). However, LPS-CM induced the neuronal shrinkage of the HT22 cells (Fig. 5c), but not cell death, as evaluated by nuclear fragmentation and condensation (Supplementary Fig. 1). The morphology of the HT22 cells was obviously improved by 6-OAP pretreatment (Fig. 5c). Studies have demonstrated that neurotoxic insult can frequently induce neurite loss that is characteristic of the early stages of neurodegeneration [47]. Thus, to determine whether inflammatory injury causes neurite breakdown, primary cortical neurons were further used for coculture experiments. We found that the proinflammatory mediators produced by BV2 cells significantly diminished the neurite length of neurons and that the effect was attenuated by 6-OAP pretreatment (Fig. 5c, d), suggesting that 6-OAP can maintain neuronal integrity and protect neurons from microglia-mediated inflammatory injury through attenuating the production of toxic proinflammatory mediators.

6-OAP suppresses the inflammatory response in an LPSchallenged mouse model

As stated above, 6-OAP can significantly inhibit the development of neuroinflammation in microglial cells. We further assessed the therapeutic potential of 6-OAP in a mouse model of neuroinflammation induced by LPS. The intraperitoneal injection of LPS for 1 day significantly induced the expression and secretion of TNF- $\alpha$ and IL-1 $\beta$ (Fig. 6a, b). Meanwhile, LPS also induced the phosphorylation of NF-KB, promoted the phosphorylation and subsequent degradation of IKB- $a$, and upregulated the expression levels of iNOS and COX-2 in hippocampal tissue (Fig. 6c), suggesting that neuroinflammation was markedly induced after 1 day of LPS treatment. However, 6-OAP administration significantly attenuated the LPS-induced production of TNF- $\alpha$ and IL-1 $\beta$, as detected by real-time PCR (Fig. 6a) and ELISA (Fig. 6b), and inhibited the induction of iNOS and COX-2 (Fig. 6c-e). Moreover, 6-OAP treatment reduced the LPS-induced phosphorylation of NF$\kappa B$ and $I K B-\alpha$ and reversed the expression level of IKB- $\alpha$ in hippocampal tissue (Fig. $6 \mathrm{c}, \mathrm{f}-\mathrm{h}$ ). These results suggest that 6-OAP has a potential role in the amelioration of LPS-induced neuroinflammation, and 6-OAP at a high dose exhibited a much stronger antineuroinflammatory effect than DEX.

6-OAP inhibits LPS-induced microglial and astrocyte activation in the LPS-treated mouse brain

Microglial and astrocyte activation are key events that contribute to the development of neuroinflammation and lead to the production of multiple proinflammatory mediators that aggravate neuronal damage. The hippocampus is the most vulnerable region in the brain and can be easily affected by inflammatory mediators. To examine the antineuroinflammatory and neuroprotective 
a

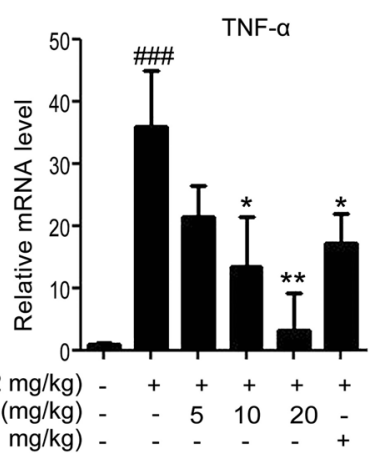

IL-1 $\beta$

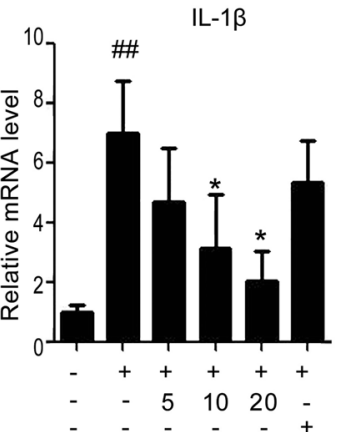

b

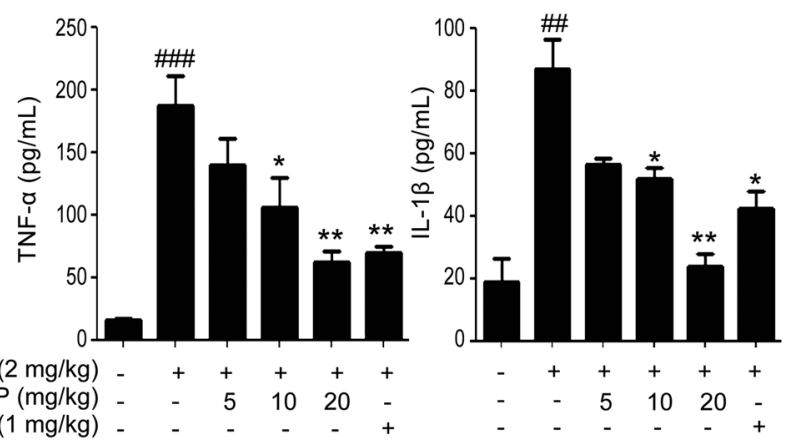

C

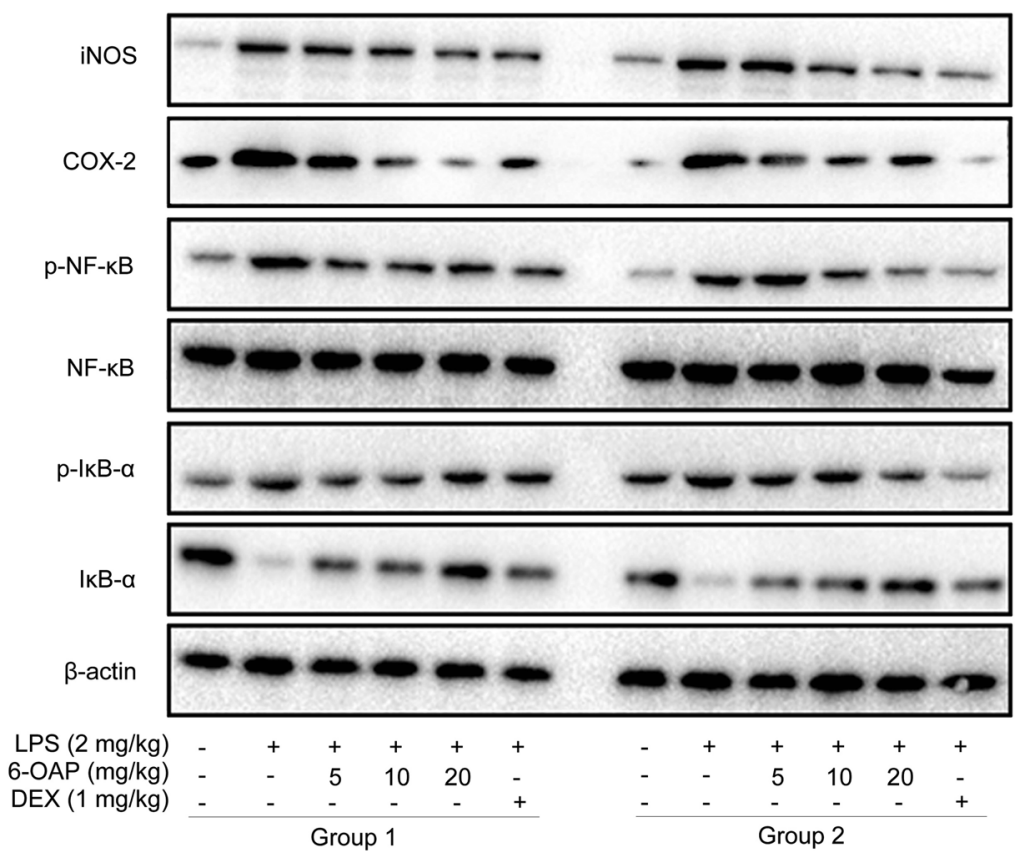

f

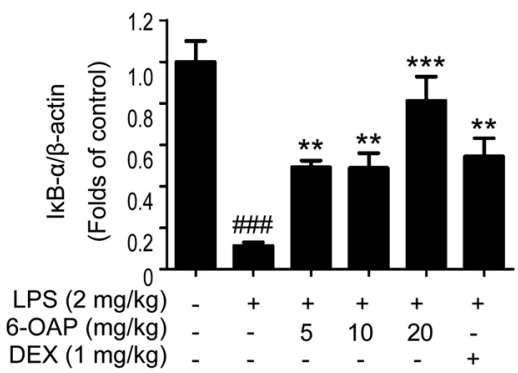

g

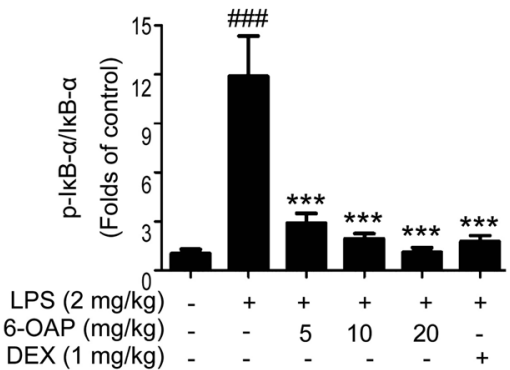

d

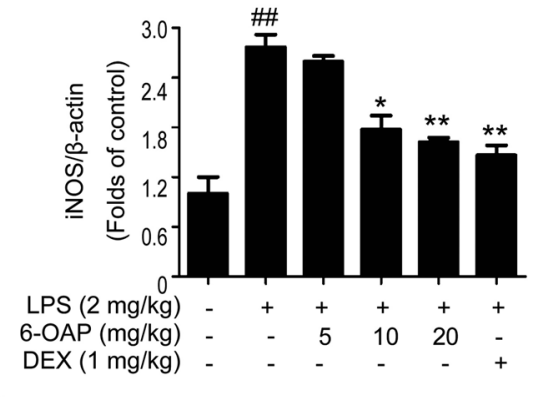

e

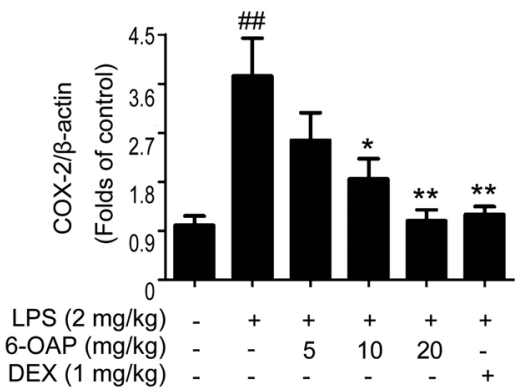

h

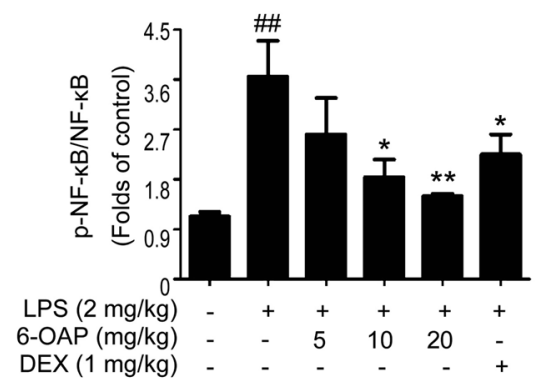

Fig. 6 6-OAP ameliorates neuroinflammation in LPS-treated mice. a The expression levels of TNF- $\alpha$ and IL-1 $\beta$ in brain tissues were analyzed by real-time PCR. $\mathbf{b}$ The production of TNF- $\alpha$ and IL-1 $\beta$ in brain tissues was examined by ELISA. $\mathbf{c}$ The protein levels of iNOS, COX-2, phospho-NF-

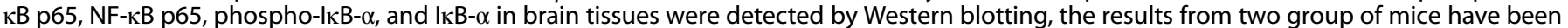
shown. $\mathbf{d}-\mathbf{h}$ The densitometry of indicated immunoblot bands was determined by ImageJ software. All data were expressed as the means \pm SEM from five mice of each group. ${ }^{\#} P<0.05,{ }^{\# \#} P<0.01,{ }^{\# \# \#} P<0.001$ versus control group. ${ }^{*} P<0.05,{ }^{* *} P<0.01,{ }^{* * *} P<0.001$ versus LPS treated

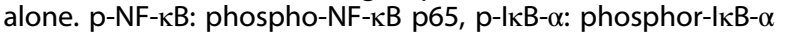

effects of 6-OAP, immunostaining was performed with antibodies against Iba1 and GFAP, specific markers of microglia and astrocytes, respectively. We found that LPS treatment for 1 day obviously increased the number of Iba1- and GFAP-positive cells in the hippocampus (Supplementary Fig. 2a-c), suggesting that microglia and astrocytes were highly activated in the brain tissue, which is consistent with the increased expression of GFAP and Iba1 in hippocampal tissue detected by Western blotting (Fig. 7d, e). Both 6-OAP and DEX treatment markedly reduced the number of microglial cells and astrocytes (Supplementary Fig. 2a-c) and decreased the expression of Iba1 and GFAP in the hippocampus (Fig. 7d, e) compared with that in the LPS-treated group. In line 
with this, 6-OAP treatment also attenuated the LPS-induced activation of microglial cells in the cortex (Supplementary Fig. 2d). Then, we examined whether 6-OAP exerts antineuroinflammatory effects via the specific inhibition of microglial and astrocyte activation. We found that LPS markedly induced TNF-a production in microglial cells and astrocytes in the hippocampal dentate gyrus (DG) region (Fig. 7a-C) but had no effect on hippocampal neurons (Supplementary Fig. 3), suggesting that activated microglia and astrocytes contribute to the production of proinflammatory factors and the development of neuroinflammation; however, 6-OAP treatment markedly attenuated the production of TNF-a in microglia and astrocytes (Fig. 7a-c). Moreover, to demonstrate the neuroprotective effects of 6-OAP, the synaptic vesicle membrane protein SYN was examined by Western blotting. 6-OAP administration markedly attenuated the LPS-induced reduction in SYN, as detected by Western blotting (Fig. 7d, e). The results demonstrate that 6-OAP exerts antineuroinflammatory and neuroprotective effects through inhibiting the activation of microglia and astrocytes.

\section{DISCUSSION}

C. minima, as a traditional Chinese medicinal herb, has been demonstrated to elicit anti-inflammatory, antioxidative, and antitumor activity [32]. Several sesquiterpene lactones that exert multiple biological activities have been isolated from C. minima $[38,48-50]$. In this study, we examined whether 6-OAP acts as a potential anti-inflammatory compound in C. minima and found that 6-OAP can significantly inhibit the activation of the NF-KB signaling pathway and decrease the expression levels of |ba1/

TNF- $\alpha$
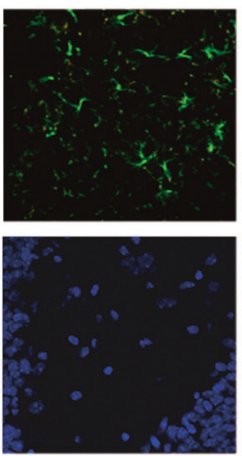

b
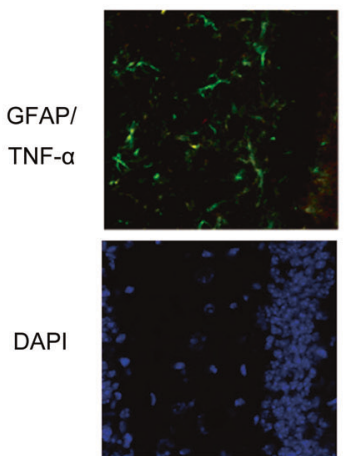

DAPI

LPS $(2 \mathrm{mg} / \mathrm{kg})$
6-OAP $(\mathrm{mg} / \mathrm{kg})$

DEX $(1 \mathrm{mg} / \mathrm{kg})$

C

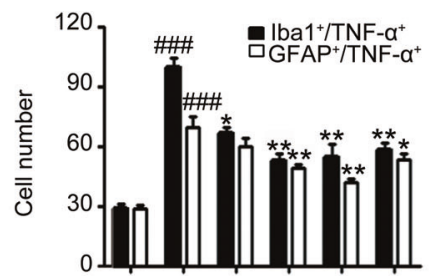

LPS $(2 \mathrm{mg} / \mathrm{kg})$ - + + + + +

$6-O A P(\mathrm{mg} / \mathrm{kg})$ - $\quad$ - 51020 -

$\operatorname{DEX}(1 \mathrm{mg} / \mathrm{kg})$ - $\quad$ - $\quad$ - $\quad$ - $\quad+$
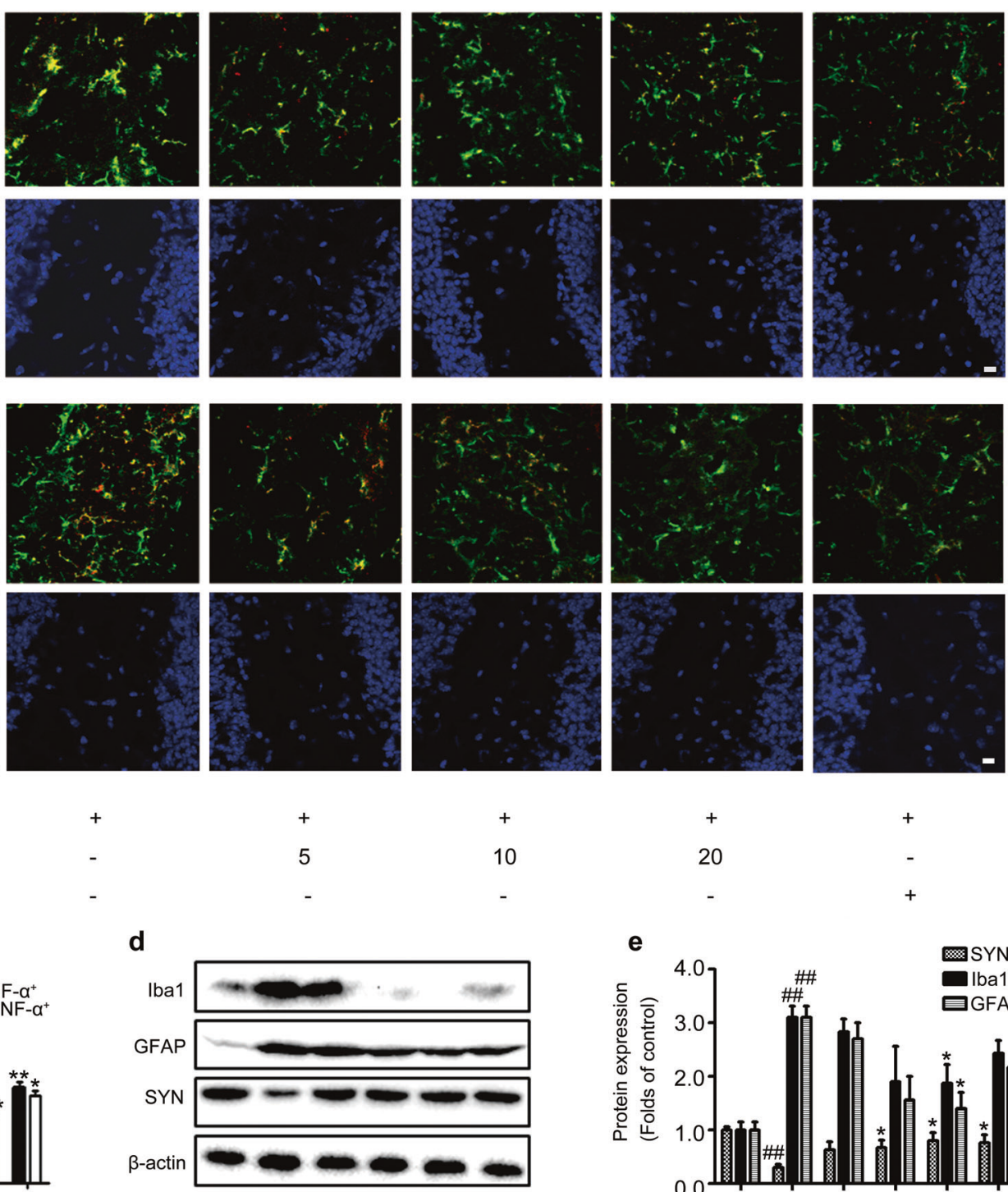

LPS $(2 \mathrm{mg} / \mathrm{kg})$

6-OAP (mg/kg)

$\operatorname{DEX}(1 \mathrm{mg} / \mathrm{kg})$

Fig. 7 6-OAP inhibits the activation of microglia and astrocyte in LPS-treated mouse brain. $\mathbf{a}$, $\mathbf{b}$ Coronal sections of mouse brain were incubated with the primary antibody against Iba1 (green) and TNF- $\alpha$ (red) (a) or GFAP (green) and TNF- $\alpha$ (red) (b) in the hippocampal DG region, DAPI was used to counter stain cell nuclei. Scale bar, $20 \mu \mathrm{m}$. c Bar graphs representing the quantification of the average cell number per field of TNF- $\alpha$-positive microglia and astrocyte in the DG region of hippocampus. d The protein levels of SYN, Iba1, and GFAP in the hippocampal tissues were detected by Western blotting. e The densitometry of indicated immunoblot bands was determined by ImageJ

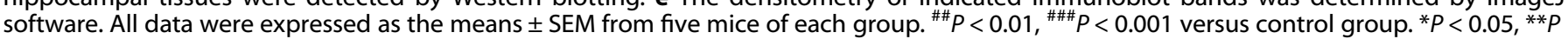
$<0.01$ versus LPS treated group 
inflammatory cytokines and enzymes. Furthermore, 6-OAP exerts antineuroinflammatory effects in an LPS-treated mouse model, demonstrating that 6-OAP has potential anti-inflammatory activity. Our previous results demonstrated that 6-OAP exhibits inhibitory effects on tumor cell proliferation. Here, we found that 6 -OAP does not affect the cell viability of microglia at the tested concentrations, indicating that 6-OAP can selectively inhibit tumor cell growth and spare normal cells. These results are consistent with our previous results that 6-OAP administration has no apparent acute toxicity in vivo [42], further supporting the safety of the agent.

The potential contribution of inflammation to the progression of neurodegenerative diseases has significantly prompted the consideration of anti-inflammatory treatment strategies. Nonsteroidal anti-inflammatory drugs and the corticosteroid DEX are commonly prescribed to treat inflammatory diseases, and these drugs appear to decrease the incidence of neurodegenerative diseases [51]. However, clinical trials of anti-inflammatory therapies have yielded relatively modest benefits [52], and these drugs have been shown to produce diverse side effects. For example, DEX, which is widely used to treat inflammatory diseases, has been shown to exhibit immunosuppressive properties and induce side effects after long-term administration [53, 54]. Recently, numerous natural products from herbal plants, such as ginsenosides and curcumin, have been reported to exert neuroprotection against inflammation and oxidative stress with fewer side effects and to exhibit promising therapeutic potential for the treatment of neuroinflammatory and neurodegenerative diseases [55]. Here, we demonstrated that the natural compound 6-OAP exerts neuroprotection via the amelioration of neuroinflammation both in vitro and in vivo. 6-OAP was shown to exhibit multiple biological activities, including the attenuation of the LPS-induced activation of COX-2, iNOS, and the NF-KB signaling pathway and the alleviation of oxidative stress through the decrease of NOX proteins. Moreover, the administration of 6-OAP at a high dose possessed a better therapeutic potential than DEX in an LPSinduced mouse model of neuroinflammation. Thus, the clinical development of natural products for neuroinflammatory diseases needs further consideration.

NF-KB plays a pivotal role in the development of inflammation, and NF-KB can regulate the expression of multiple proinflammatory factors and enzymes [16]. In this study, we also demonstrated that 6-OAP can significantly inhibit the LPS-induced activation of NF-KB and decrease the expression of inflammatory cytokines, COX-2, and iNOS. A previous study also found that 6-OAP can inhibit the TNF-a-induced activation of NF-KB [41], suggesting that NF-KB plays an important role in the mediation of the antiinflammatory effects of 6-OAP. However, it is possible that 6-OAP can antagonize many steps in the NF- $\mathrm{KB}$ inflammatory cascade, and the identification of the targets of 6-OAP is worth further investigation.

Inflammation can induce the generation of oxidative stress and vice versa. Increasing evidence has demonstrated that NOX family members can mediate ROS generation, and NOX-2 and NOX-4 have been reported to be mainly responsible for oxidative stress induction in the CNS [26]. In our study, we also found that LPS can markedly increase the expression levels of NOX-2 and NOX-4 and induce ROS production in microglial cells, indicating that NOX protein family members mediate LPS-induced ROS generation. However, 6-OAP administration was shown to decrease the expression levels of NOX-2 and NOX-4 and reduce ROS production in microglial cells, suggesting that 6-OAP can suppress ROS generation by decreasing the expression of NOX proteins in the CNS and that this effect can attenuate the development of neuroinflammatory diseases.

Both microglial cells and astrocytes are widely accepted to contribute to the development of neuroinflammation. Microglial cells, which recruit astrocytes by secreting cytokines and acute-phase proteins, are normally the first cells to be activated in response to injury and infection. It has been reported that LPS treatment can induce the development of neuroinflammation within $24 \mathrm{~h}$ via the activation of microglial cells and astrocytes [56]. In line with previous reports, our study also found that a single dose of LPS can induce a neuroinflammatory response, characterized by the accumulation of activated microglial cells and astrocytes in the hippocampus and cortex, in mice. 6-OAP administration can markedly attenuate the LPS-induced activation of microglia and astrocytes and decrease the generation of inflammatory cytokines and enzymes. Furthermore, studies have reported that sustained LPS treatment induces amyloidogenesis and astrogliosis, which result in neuronal damage and memory dysfunction, and acute LPS administration can potently induce synaptic damage $[57,58]$. Our study demonstrated that the proinflammatory mediators produced by activated microglial cells can significantly induce neurite and synaptic loss both in vitro and in vivo, and we did not observe obvious apoptotic cell death after short-term inflammatory stimulation, indicating that 6-OAP treatment can potentially protect neurons from inflammatory injury.

In conclusion, we have demonstrated that 6-OAP exerts antineuroinflammatory and neuroprotective effects through inhibiting the production of proinflammatory factors and attenuating the activation of inflammatory enzymes and NF-KB signaling both in vitro and in vivo, suggesting that 6-OAP has promising therapeutic potential for neuroinflammatory diseases.

\section{ACKNOWLEDGEMENTS}

This work was supported by Guangzhou Science Technology and Innovation Commission Technology Research Projects (201805010005), the National Natural Science Foundation of China (81473740, 81673627, 81673946, 81802776), the National Science Fund for Distinguished Young Scholars (81525026), and the National Key Research and Development Program of China "Research and Development of Comprehensive Technologies on Chemical Fertilizer and Pesticide Reduction and Synergism" (2017YFD0201402).

\section{AUTHOR CONTRIBUTIONS}

YLZ, YMY, HFP, YXC and YQL designed the experiments, collected and analyzed the data, and drafted the paper. YLZ, SYL and DHH performed the cellular experiments, YLZ, SYL and DHH performed the molecular experiments, and YLZ, SX, SFW, WL and YQL participated in animal surgery and data collection. YLZ, QW, LH, HFP, YXC and YQL revised the paper. All authors have read and approved the final submitted paper.

\section{ADDITIONAL INFORMATION}

The online version of this article (https://doi.org/10.1038/s41401-019-0261-5) contains supplementary material, which is available to authorized users.

Competing interests: The authors declare no competing interests.

\section{REFERENCES}

1. Amor $S$, Puentes $F$, Baker $D$, van der Valk P. Inflammation in neurodegenerative diseases. Immunology. 2010;129:154-69.

2. Eikelenboom P, Bate C, Van Gool WA, Hoozemans JJ, Rozemuller JM, Veerhuis R, Williams A. Neuroinflammation in Alzheimer's disease and prion disease. Glia. 2002;40:232-39.

3. Kim YS, Joh TH. Microglia, major player in the brain inflammation: their roles in the pathogenesis of Parkinson's disease. Exp Mol Med. 2006;38:333-47.

4. McGeer EG, McGeer PL. Inflammatory processes in Alzheimer's disease. Prog Neuropsychopharmacol Biol Psychiatry. 2003;27:741-49.

5. Sanders P, De Keyser J. Janus faces of microglia in multiple sclerosis. Brain Res Rev. 2007;54:274-85.

6. Liu B, Hong JS. Role of microglia in inflammation-mediated neurodegenerative diseases: mechanisms and strategies for therapeutic intervention. J Pharmacol Exp Ther. 2003;304:1-7.

7. Al-Amin MM, Reza HM. Neuroinflammation: contemporary anti-inflammatory treatment approaches. Neurosci (Riyadh). 2014;19:87-92. 
8. Walsh JG, Muruve DA, Power C. Inflammasomes in the CNS. Nat Rev Neurosci. 2014;15:84-97.

9. Whitney NP, Eidem TM, Peng H, Huang Y, Zheng JC. Inflammation mediates varying effects in neurogenesis: relevance to the pathogenesis of brain injury and neurodegenerative disorders. J Neurochem. 2009;108:1343-59.

10. Block ML, Zecca L, Hong JS. Microglia-mediated neurotoxicity: uncovering the molecular mechanisms. Nat Rev Neurosci. 2007;8:57-69.

11. Morales I, Guzman-Martinez L, Cerda-Troncoso C, Farias GA, Maccioni RB. Neuroinflammation in the pathogenesis of Alzheimer's disease. A rational framework for the search of novel therapeutic approaches. Front Cell Neurosci. 2014;8:112.

12. Siopi $E$, Llufriu-Daben $G$, Cho AH, Vidal-Lletjos S, Plotkine $M$, Marchand-Leroux $C$ et al. Etazolate, an alpha-secretase activator, reduces neuroinflammation and offers persistent neuroprotection following traumatic brain injury in mice. Neuropharmacology. 2013;67:183-92.

13. Brown J, Wang $H$, Hajishengallis GN, Martin M. TLR-signaling networks: an integration of adaptor molecules, kinases, and cross-talk. J Dent Res. 2011;90:417-27.

14. Yao L, Kan EM, Lu J, Hao A, Dheen ST, Kaur C, Ling EA. Toll-like receptor 4 mediates microglial activation and production of inflammatory mediators in neonatal rat brain following hypoxia: role of TLR4 in hypoxic microglia. J Neuroinflamm. 2013;10:23.

15. Berger T, Saunders ME, Mak TW. Dissection of signaling in inflammation: three novel inflammatory regulators. Cold Spring Harb Symp Quant Biol. 2013;78:141-47.

16. Hayden MS, Ghosh S. Shared principles in NF-kappaB signaling. Cell. 2008;132:344-62.

17. Saha RN, Pahan K. Regulation of inducible nitric oxide synthase gene in glial cells. Antioxid Redox Signal. 2006;8:929-47.

18. von Bernhardi R, Eugenin-von Bernhardi L, Eugenin J. Microglial cell dysregulation in brain aging and neurodegeneration. Front Aging Neurosci. 2015;7:124.

19. Woodling NS, Andreasson KI. Untangling the web: toxic and protective effects of neuroinflammation and PGE2 signaling in Alzheimer's disease. ACS Chem Neurosci. 2016;7:454-63.

20. Ben Mkaddem S, Pedruzzi E, Werts C, Coant N, Bens M, Cluzeaud F, et al. Heat shock protein gp96 and NAD(P)H oxidase 4 play key roles in Toll-like receptor 4activated apoptosis during renal ischemia/reperfusion injury. Cell Death Differ. 2010;17:1474-85

21. Brown GC. Mechanisms of inflammatory neurodegeneration: iNOS and NADPH oxidase. Biochem Soc Trans. 2007;35:1119-21.

22. Li Q, Spencer NY, Oakley FD, Buettner GR, Engelhardt JF. Endosomal Nox2 facilitates redox-dependent induction of NF-kappaB by TNF-alpha. Antioxid Redox Signal. 2009;11:1249-63.

23. Rojo Al, McBean G, Cindric M, Egea J, Lopez MG, Rada P, et al. Redox control of microglial function: molecular mechanisms and functional significance. Antioxid Redox Signal. 2014;21:1766-801.

24. Anrather J, Racchumi G, ladecola C. NF-kappaB regulates phagocytic NADPH oxidase by inducing the expression of gp91phox. J Biol Chem. 2006;281:5657-67.

25. Gauss KA, Nelson-Overton LK, Siemsen DW, Gao Y, DeLeo FR, Quinn MT. Role of NF-kappaB in transcriptional regulation of the phagocyte NADPH oxidase by tumor necrosis factor-alpha. J Leukoc Biol. 2007;82:729-41.

26. Nayernia Z, Jaquet V, Krause KH. New insights on NOX enzymes in the central nervous system. Antioxid Redox Signal. 2014;20:2815-37.

27. Choi DK, Koppula S, Suk K. Inhibitors of microglial neurotoxicity: focus on natural products. Molecules. 2011;16:1021-43.

28. Shal B, Ding W, Ali H, Kim YS, Khan S. Anti-neuroinflammatory potential of natural products in attenuation of Alzheimer's disease. Front Pharmacol. 2018;9:548.

29. Suk K, Ock J. Chemical genetics of neuroinflammation: natural and synthetic compounds as microglial inhibitors. Inflammopharmacology. 2012;20:151-8.

30. Schwikkard S, van Heerden FR. Antimalarial activity of plant metabolites. Nat Prod Rep. 2002;19:675-92.

31. Taylor RS, Towers GH. Antibacterial constituents of the Nepalese medicinal herb, Centipeda minima. Phytochemistry. 1998;47:631-4.

32. Huang SS, Chiu CS, Lin TH, Lee MM, Lee CY, Chang SJ, et al. Antioxidant and antiinflammatory activities of aqueous extract of Centipeda minima. J Ethnopharmacol. 2013;147:395-405.

33. Liu ZG, Yu HM, Wen SL, Liu YL. Histopathological study on allergic rhinitis treated with Centipeda minima. Zhongguo Zhong Yao Za Zhi. 2005;30:292-4.

34. Wu JB, Chun YT, Ebizuka Y, Sankawa U. Biologically active constituents of Centipeda minima: sesquiterpenes of potential anti-allergy activity. Chem Pharm Bull (Tokyo). 1991;39:3272-5.
35. Liang H, Bao F, Dong X, Tan R, Zhang C, Lu Q, et al. Antibacterial thymol derivatives isolated from Centipeda minima. Molecules. 2007;12:1606-13.

36. Liang HX, Bao FK, Dong XP, Zhu HJ, Lu XJ, Shi M, et al. Two new antibacterial sesquiterpenoids from Centipeda minima. Chem Biodivers. 2007;4:2810-6.

37. Wu P, Li XG, Liang N, Wang GC, Ye WC, Zhou GX, et al. Two new sesquiterpene lactones from the supercritical fluid extract of Centipeda minima. J Asian Nat Prod Res. 2012;14:515-20.

38. Wu P, Su MX, Wang Y, Wang GC, Ye WC, Chung HY, et al. Supercritical fluid extraction assisted isolation of sesquiterpene lactones with antiproliferative effects from Centipeda minima. Phytochemistry. 2012;76:133-40.

39. Ding LF, Liu Y, Liang HX, Liu DP, Zhou GB, Cheng YX. Two new terpene glucosides and antitumor agents from Centipeda minima. J Asian Nat Prod Res. 2009;11:732-36.

40. Oh HM, Kwon BM, Baek NI, Kim SH, Lee JH, Eun JS, et al. Inhibitory activity of 6-Oangeloylprenolin from Centipeda minima on farnesyl protein transferase. Arch Pharm Res. 2006;29:64-6.

41. Liu $Y$, Chen $X Q$, Liang $H X$, Zhang FX, Zhang B, Jin J, et al. Small compound 6-Oangeloylplenolin induces mitotic arrest and exhibits therapeutic potentials in multiple myeloma. PLoS ONE. 2011;6:e21930.

42. Liu YQ, Wang XL, Cheng X, Lu YZ, Wang GZ, Li XC, et al. Skp1 in lung cancer: clinical significance and therapeutic efficacy of its small molecule inhibitors. Oncotarget. 2015;6:34953-67.

43. Saura J, Tusell JM, Serratosa J. High-yield isolation of murine microglia by mild trypsinization. Glia. 2003;44:183-89.

44. Li Y, Wang J, Sheng JG, Liu L, Barger SW, Jones RA, et al. S100 beta increases levels of beta-amyloid precursor protein and its encoding mRNA in rat neuronal cultures. J Neurochem. 1998;71:1421-8.

45. Meijering $E$, Jacob $M$, Sarria JC, Steiner $P$, Hirling $H$, Unser $M$. Design and validation of a tool for neurite tracing and analysis in fluorescence microscopy images. Cytom A. 2004;58:167-76.

46. Tam WY, Ma CH. Bipolar/rod-shaped microglia are proliferating microglia with distinct M1/M2 phenotypes. Sci Rep. 2014;4:7279.

47. Chuang KA, Li MH, Lin $\mathrm{NH}$, Chang $\mathrm{CH}$, Lu IH, Pan IH, et al. Rhinacanthin $\mathrm{C}$ alleviates amyloid-beta fibrils' toxicity on neurons and attenuates neuroinflammation triggered by LPS, amyloid-beta, and interferon-gamma in glial cells. Oxid Med Cell Longev. 2017;2017:5414297.

48. Wu JB, Chun YT, Ebizuka Y, Sankawa U. Biologically active constituents of Centipeda minima: isolation of a new plenolin ester and the antiallergy activity of sesquiterpene lactones. Chem Pharm Bull (Tokyo). 1985;33:4091-4.

49. Su M, Li Y, Chung HY, Ye W. 2beta-(Isobutyryloxy)florilenalin, a sesquiterpene lactone isolated from the medicinal plant Centipeda minima, induces apoptosis in human nasopharyngeal carcinoma CNE cells. Molecules. 2009;14:2135-46.

50. Huang W, Yu X, Liang N, Ge W, Kwok HF, Lau CB, et al. Anti-angiogenic activity and mechanism of sesquiterpene lactones from Centipeda minima. Nat Prod Commun. 2016;11:435-8.

51. Zandi PP, Anthony JC, Hayden KM, Mehta K, Mayer L, Breitner JC, et al. Reduced incidence of $\mathrm{AD}$ with NSAID but not $\mathrm{H} 2$ receptor antagonists: the Cache County Study. Neurology. 2002;59:880-6.

52. Aisen PS, Schafer KA, Grundman M, Pfeiffer E, Sano M, Davis KL, et al. Effects of rofecoxib or naproxen vs placebo on Alzheimer disease progression: a randomized controlled trial. JAMA. 2003;289:2819-26.

53. Kroot EJ, Huisman AM, Van Zeben J, Wouters JM, Van Paassen HC. Oral pulsed dexamethasone therapy in early rheumatoid arthritis: a pilot study. Ann N Y Acad Sci. 2006;1069:300-6.

54. Meneses G, Gevorkian G, Florentino A, Bautista MA, Espinosa A, Acero G, et al. Intranasal delivery of dexamethasone efficiently controls LPS-induced murine neuroinflammation. Clin Exp Immunol. 2017;190:304-14.

55. Wang J, Song Y, Chen Z, Leng SX. Connection between systemic inflammation and neuroinflammation underlies neuroprotective mechanism of several phytochemicals in neurodegenerative diseases. Oxid Med Cell Longev. 2018;2018:1972714.

56. Fu HQ, Yang T, Xiao W, Fan L, Wu Y, Terrando N, et al. Prolonged neuroinflammation after lipopolysaccharide exposure in aged rats. PLoS ONE. 2014;9: e106331.

57. Chen M, Chang YY, Huang S, Xiao LH, Zhou W, Zhang LY, et al. Aromaticturmerone attenuates LPS-induced neuroinflammation and consequent memory impairment by targeting TLR4-dependent signaling pathway. Mol Nutr Food Res. 2018;62:201700281.

58. Gu SM, Park MH, Hwang CJ, Song HS, Lee US, Han SB, et al. Bee venom ameliorates lipopolysaccharide-induced memory loss by preventing NF-kappaB pathway. J Neuroinflamm. 2015;12:124. 